\title{
Evaluating Clouds in Long-Term Cloud-Resolving Model Simulations with Observational Data
}

\author{
Xiping Zeng ${ }^{1,2}$, Wei-Kuo Tao ${ }^{2}$, Minghua Zhang $^{3}$, Christa Peters-Lidard ${ }^{4}$, Stephen Lang ${ }^{2,6}$, \\ Joanne Simpson ${ }^{2}$, Sujay Kumar ${ }^{1,4}$, Shaocheng Xie ${ }^{5}$, Joseph L. Eastman ${ }^{1,4}$, Chung-Lin \\ Shie $^{1,2}$, and James V. Geiger ${ }^{4}$ \\ ${ }^{1}$ Goddard Earth Sciences and Technology Center, University of Maryland at Baltimore \\ County, Baltimore, Maryland \\ ${ }^{2}$ Laboratory for Atmospheres, NASA Goddard Space Flight Center, Greenbelt, Maryland \\ ${ }^{3}$ Marine Sciences Research Center, State University of New York at Stony Brook, New York \\ ${ }^{4}$ Laboratory for Hydrospheric Processes, NASA Goddard Space Flight Center, Greenbelt, \\ Maryland \\ ${ }^{5}$ Atmospheric Sciences Division, Lawrence Livermore National Laboratory, Livermore, \\ California \\ ${ }^{6}$ Science Systems and Applications Inc., Greenbelt, Maryland
}

To be submitted to the Journal of the Atmospheric Sciences

May 3, 2006

Corresponding author address: Dr. Xiping Zeng, Mail Code 613.1, NASA Goddard Space Flight Center, Greenbelt, MD 20771. Email: zeng@agnes.gsfc.nasa.gov 


\begin{abstract}
Two 20-day, continental midlatitude cases are simulated with a three-dimensional (3D) cloud-resolving model (CRM) and compared to Atmospheric Radiation Measurement (ARM) data. This evaluation of long-term cloud-resolving model simulations focuses on the evaluation of clouds and surface fluxes.

All numerical experiments, as compared to observations, simulate surface precipitation well but over-predict clouds, especially in the upper troposphere. The sensitivity of cloud properties to dimensionality and other factors is studied to isolate the origins of the over prediction of clouds. Due to the difference in buoyancy damping between $2 \mathrm{D}$ and $3 \mathrm{D}$ models, surface precipitation fluctuates rapidly with time, and spurious dehumidification occurs near the tropopause in the 2D CRM.

Surface fluxes from a land data assimilation system are compared with ARM observations. They are used in place of the ARM surface fluxes to test the sensitivity of simulated clouds to surface fluxes. Summertime simulations show that surface fluxes from the assimilation system bring about a better simulation of diurnal cloud variation in the lower troposphere.
\end{abstract}




\section{Introduction}

The representation of clouds is one of the most important uncertainties in general circulation models (GCMs) in simulating the global water and energy cycle (e.g., Cess et al. 1990; Zhang et al. 2005). Currently, cloud-resolving models (CRMs) are being incorporated into large-scale dynamic frameworks (e.g., GCMs) to facilitate the interaction between clouds and large-scale circulations in place of conventional cumulus parameterization (Emanuel and Raymond 1993) as an alternative approach (e.g., Grabowski 2001; Khairoutdinov and Randall 2001; Raymond and Zeng 2005; Khairoutdinov et al. 2005; Chern et al. 2005). This approach is referred to as a superparameterization or multi-scale modeling framework (MMF, Randall et al. 2003). The approach has merit, since no assumption is introduced on the causality between cumulus clouds and large-scale circulations. A key question is whether current CRMs can function in a MMF as expected. This question can be addressed by evaluating long-term CRM simulations against observations. Here long-term simulation means a period comparable to the long timescale in the approach to radiative-convective equilibrium (Tompkins and Craig 1998), which is around three weeks.

Consider a CRM in an ideal MMF with no computational limits. The CRM can be represented in a computationally expensive way [e.g., a three-dimensional (3D) framework with sufficient gridpoints]. When the CRM is driven with prescribed largescale forcing, the difference between the modeling results and observations is attributed to model physics instead of computational issues [e.g., a two-dimensional (2D) framework, insufficient gridpoints]. Thus, the difference between the modeling results 
and observations provides insights on improving the CRMs that are currently being used in MMFs. In this direction, the Goddard Cumulus Ensemble (GCE) model is evaluated with data collected in the Atmospheric Radiation Measurement (ARM) program. Two 20-day, continental midlatitude cases were selected for this purpose.

CRM evaluation can be traced back two decades. Although real clouds and cloud systems are 3D, most CRMs used today are still 2D due to computer resources (Krueger 1988; Xu and Randall 1996; Wu et al. 1998; and many others). Only a few 3D CRMs (e.g., Tao and Soong 1986; Lipps and Hemler 1986) have been used to study the response of clouds to large-scale forcing. Previous studies showed that the collective thermodynamic feedback effect, and the vertical transports of mass, sensible heat, and moisture were quite similar between $2 \mathrm{D}$ and $3 \mathrm{D}$ simulations (e.g., Tao et al. 1987). Recently, several 3D CRM experiments were performed for 7-day periods for tropical cloud systems with large horizontal domains $\left(500 \times 500 \mathrm{~km}^{2}\right)$ at the National Center for Atmospheric Research (Grabowski et al. 1998; Wu et al. 1998), NOAA/GFDL (Donner et al. 1999), Colorado State University (Khairoutdinov and Randall 2003) and NASA Goddard Space Flight Center (Tao 2003). Grabowski et al. (1998) found that cloud statistics as well as surface precipitation are significantly different between 2D and 3D simulations when clouds and radiation are fully interactive. At Goddard, Tao (2003) found that the 3D-modeled water vapor budget is in much better agreement with observations in the lower troposphere than its $2 \mathrm{D}$ counterpart.

In this study, the 3D GCE model is used to simulate continental midlatitude clouds for twenty days, longer than most previous 3D CRM simulations, to evaluate the simulated cloud residue (i.e., cloud ice, cloud water and water vapor). Since cloud residue is a 
natural consequence of cloud growth, temporal and accumulated model surface precipitation is compared with observations, because surface precipitation rate can be regarded as a measure of cloud growth. Special attention is paid to the sensitivity of clouds to dimensionality.

Model evaluation depends strongly on observational data quality (Moncrieff et al. 1997). Some recent field experiments [e.g., the ARM Spring 2000 Intensive Operational Period (IOP) and the ARM 2002, International $\mathrm{H}_{2} \mathrm{O}$ Project (IHOP) in 2002] have provided comprehensive observational data (e.g., Ackerman and Stokes 2003; Weckwerth et al. 2004) for model evaluation. The observed cloud properties from the ARM Spring 2000 IOP, for example, are the best in the fourteen-year history of the ARM program (Xu et al. 2005).

This study involves two twenty-day observation periods during two field experiments. One is from the ARM IOP 2000 and the other IHOP 2002. Some of the cloud systems in these experiments have already been studied for specific purposes, such as the life cycle of convective clouds and as a setting for a model inter-comparison (Wakimoto et al. 2004; Xie et al. 2005; Xu et al. 2005). Xie et al. (2005) and Xu et al. (2005) focused on two short periods in the ARM IOP 2000 to compare four 2D CRMs as well as eight single-column models with observations. They suggested that 3D CRM simulations be done to narrow down the origins of differences between the 2D CRMs and observations.

This paper evaluates clouds in long-term CRM simulations. It is organized as follows. Section 2 describes the models and observational data used. Sections 3 and 4 analyze the modeling results for springtime and summertime cloud systems, respectively. And, sections 5 and 6 give a discussion and summary, respectively. 


\section{Design of numerical experiments}

\section{a. Model description}

A single-column CRM, which differs from the two-column models designed to account for the interaction between convection and large-scale circulations (Nilsson and Emanuel 1999; Sobel and Bretherton 2000; Raymond and Zeng 2000, 2005), is used here to test the response of clouds to prescribed large-scale forcing derived from observational data. The model structure follows previous ones (e.g., Johnson et al. 2002; Xie et al. 2005; Xu et al. 2005) except for surface flux input. In the current framework, clouds are simulated with the GCE model, large-scale forcing data come from observations, and surface fluxes in the lower boundary come from either observations or a land data assimilation system.

The GCE model is detailed in Tao and Simpson (1993) and Tao et al. (2003), which describes its development and main features. Its application to studies of precipitation processes and improving satellite retrievals can be found in Simpson and Tao (1993) and Tao (2003). The model is non-hydrostatic and anelastic. It can be used in two- or threedimensions with cyclic lateral boundary conditions. Solar and infrared radiative transfer processes (four-stream discrete-ordinate scattering) are included. Their impact on cloud development associated with cloud-radiation interaction has been assessed (Tao et al. 1996). Subgrid-scale (turbulent) processes in the model are parameterized using a scheme based on Klemp and Wilhelmson (1978) and Soong and Ogura (1980). The effects of both dry and moist processes on the generation of subgrid-scale kinetic energy have been incorporated. A three-class ice formulation (3ICE), namely that by Lin et al. (1983), was 
used. The sedimentation of ice crystals was recently included in the GCE based on Heymsfield and Donner (1990) and Heymsfield and Iaquinta (2000) and was discussed in detail in Hong et al. (2004). All scalar variables (temperature, water vapor, and all hydrometeors) are calculated with a positive definite advection scheme (Smolarkiewicz and Grabowski 1990). Results from the positive definite advection scheme are in better agreement with observations for tropical cloud syștems (Johnson et al. 2002).

In addition to the ARM surface fluxes, for land surface sensitivity experiments, the surface fluxes were extracted from the Land Information System (LIS, Kumar et al. 2004, http://lis.gsfc.nasa.gov/). LIS is a high performance land surface modeling and data assimilation system. It contains numerous land surface models (LSMs) that can be driven by a variety of atmospheric forcing from point to gridded data. For this study the NOAH LSM was employed. This LSM simulates soil moisture (both liquid and frozen), soil temperature, skin temperature, snowpack depth, snowpack water equivalent (and hence snowpack density), canopy water content, and the energy flux and water flux terms of the surface energy and surface water balances. The LSM land-surface parameters were initialized with University of Maryland $1 \mathrm{~km}$ datasets for vegetation and land-sea masks (Hansen et. al. 2005). Climatological datasets were ingested in order to initialize other vegetation parameters such as albedo and green vegetation fraction. Soils types were set using the State Soil Geographic Database for State [Soil Survey Staff, Natural Resources Conservation Service, United States Department of Agriculture], which has a $1 \mathrm{~km}$ horizontal resolution. Initial soil water and temperature profiles were also assigned according to climatology. 
The LSM was integrated for 15 years up through the study period. For the period 1985 through 1996, NCEP reanalysis data (the NCEP reanalysis data was obtained from the NOAA-CIRES ESRL/PSD Climate Diagnostics branch, Boulder, Colorado, USA, web site at http://www.cdc.noaa.gov/) was used for the atmospheric forcing. After this period, 1/8th degree atmospheric forcing was provided by the North American Land Data Assimilation System (NLDAS, Cosgrove et. al. 2003), which incorporates high resolution GOES radiation and Stage IV precipitation fields into the NCEP ETA Data Assimilation System (EDAS). Modeled fluxes and temperature fields were then evaluated against a variety of surface station data and found to be in excellent agreement with observations. The modeled latent and sensible heat fluxes were then extracted for use in the GCE model.

\section{b. Data}

Two cases are studied in the present paper. The first one is the ARM Spring 2000 IOP, which was also used in the ARM CPM WG Case 4 Study (Xie et al. 2005; Xu et al. 2005). This dataset starts at 1730 UTC 1 March and ends at 0830 UTC 22 March 2000. The second case covers the period from 2030 UTC 25 May to 830 UTC 14 June 2002 for the same ARM domain, which overlaps IHOP 2002. The two cases represent springtime and summertime midlatitude clouds, respectively.

The ARM observational data used are classified into two parts: forcing and evaluation data. Large-scale forcing data (i.e., vertical motion and horizontal advective tendencies of temperature and moisture) are derived using data collected from the two ARM IOPs and the variational analysis approach described in Zhang and Lin (1997) and Zhang et al. (2001). The values represent the mean ARM Cloud and Radiation Testbed (CART) 
domain rather than a single point (Zhang et al. 2001). The surface fluxes are obtained from site-wide averages of observed fluxes from the ARM Energy Balance Bowen Ratio (EBBR) stations. The fluxes are assumed to be horizontally uniform in the model. The LIS fluxes, which provide an alternate source for surface fluxes, are used for comparison and are discussed in section 4.b as well as in the preceding subsection.

Evaluation data include observed temperature and humidity as well as others on clouds and precipitation. Temperature and humidity are observed every three hours during the IOPs. Cloud liquid water content and ice water content are obtained as ARM MICRO-BASE products (Miller et al. 2003). Vertical profiles of cloud fraction are derived from the hydrometeor frequencies from the Active Remotely Sensed Cloud Layers (ARSCL) data archive (Clothiaux et al. 2000). The uncertainties in those quantities were discussed by Xie et al. (2005).

\section{c. Numerical experiments}

A default numerical experiment is set up with a $1 \mathrm{~km}$ horizontal resolution, vertical resolution that ranges from $42.5 \mathrm{~m}$ at the bottom to $1 \mathrm{~km}$ at the top, and an integration time step of $6 \mathrm{~s}$. The GCE model uses $128 \times 128 \times 41$ gridpoints and is integrated for 20 days except for specific tests. The model domain is located over the ARM Southern Great Plains (SGP) site with the center at $36.6 \mathrm{~N}$ and $96.5 \mathrm{~W}$.

The numerical experiments discussed in the paper are listed in Table 1. There are two control experiments $\mathrm{C} 00$ and $\mathrm{C} 02$ for the 2000 and 2002 cases, respectively. Experiments C00, B00 and G00 are used to examine the sensitivity of clouds to domain structure. C00 is a springtime cloud simulation. Its results are compared with those of other CRMs as part of a model inter-comparison. In the experiment, surface fluxes come from the ARM 
observations (Fig. 1). Experiment B00 uses $256 \times 256 \times 41$ gridpoints and a $2 \mathrm{~km}$ horizontal resolution for a bigger domain to test the sensitivity of clouds to domain size. In contrast to $\mathrm{B} 00$, experiment $\mathrm{G} 00$ uses $256 \times 256 \times 41$ gridpoints but a $1 \mathrm{~km}$ horizontal resolution to test the sensitivity of clouds to grid size.

Two experiments test the sensitivity of clouds to cloud microphysics. Experiment M00ICE takes account of cloud ice sedimentation, and M00RH uses the microphysics parameterization scheme of Rutledge and Hobbs (1984). In addition, a 2D experiment D00 is used to assess the sensitivity to dimensionality, linking the 3D GCE model to other 2D CRMs in the comparison.

Control experiment $\mathrm{C} 02$, contrasting springtime $\mathrm{C} 00$ case, is a summertime cloud simulation. As with $\mathrm{C} 00$, its surface fluxes come from ARM observations and are shown in Fig. 2. As compared by Figs. 1 and 2, the 2002 case possesses strong surface latent heat flux both in amplitude and daily average.

In contrast to $\mathrm{C} 02$, experiment L02 uses surface fluxes from LIS, a land data assimilation system, that are then averaged horizontally for comparison. A snap-shot of the spatial distribution of the LIS surface fluxes at day 1 is shown in Fig. 3. The horizontally-averaged surface fluxes are also shown in Fig. 2 in comparison with the ARM surface fluxes. As shown in the figure, the latent heat fluxes from ARM and LIS are very close while the sensible heat fluxes are different, especially from day 4 to 9 . Experiment L02 tests the sensitivity of clouds to surface fluxes from different sources.

\section{The 2000 case for springtime clouds}

a. Control experiment (COO) 
The control numerical experiment (C00) falls within the spring of 2000: Part of the large-scale forcing data over the CART domain is displayed in Fig. 4, including largescale horizontal temperature advection, horizontal advection of water vapor mixing ratio, and large-scale vertical velocity. The surface latent and sensible heat fluxes are shown in Fig. 1. These forcing data start at 1730 UTC 1 March and end on 21 March 2000. Various synoptic systems pass through the domain in the following sequence: a synoptic cyclogenesis event (1-4 March), a cold front leg (5-8), an upper-level trough (9-11), nonprecipitating clouds (12-15), a cold front with frontognesis (15-19), and stationary fronts $(20-22)$.

The 3D GCE model with Lin et al. (1983) microphysics is used to simulate the twenty-day period. Modeled surface precipitation is compared with observations in Fig. 5 with thin and thick lines, respectively. In general, model surface precipitation agrees well with observations. Differences in intensity exist at days $6.5,12.5$ and 14.5. The accumulated surface precipitation amount is $6.3 \%$ smaller than was observed. Both modeled and observed surface precipitation rates have similar probability distribution functions (PDFs).

Time-pressure cross sections of retrieved liquid and ice water contents are displayed in Fig. 6. Since retrievals have been well tested on thin non-precipitating clouds but not on thick precipitating clouds (Dong and Mace 2003), contour lines in the figure indicate the relative magnitude of the water contents. However, the contour line dividing zero from non-zero water contents shows clearly the extent of the clouds. Such distributions of water contents are used to evaluate the modeling results. 
The domain-averaged water contents in the model are displayed in Fig. 7, where the liquid and ice water contents are defined as the total mixing ratios of liquid and ice water species, respectively. As shown in Figs. 6 and 7, the distribution of liquid water content in the model is similar to that retrieved. However, the distribution of model ice water content is quite different from the retrieved. Model ice water, in contrast to the retrieved, persists above 265 hpa as a residue of modeled clouds.

Time-pressure cross sections of observed relative humidity and cloud fraction are shown in Fig. 8 and cross sections of the same variables from the model in Fig. 9. A grid box in the model is defined as "cloudy" when the radar reflectivity $\mathrm{dB} Z_{e} \geq-35$, where the radar reflectivity is estimated from the mixing ratios of all water species using the algorithm of Luo et al. (2003). The distributions, as shown in Figs. 8 and 9, are similar for the main precipitation events such as those at day $1,6.5,9.5$, and 15 . However, the distribution of observed cloud fraction has many more fine structures than does the model. Modeled relative humidity, as shown in Figs. 8 and 9, is larger than was observed in the upper troposphere. The modeled relative humidity near $265 \mathrm{hpa}$ increases gradually with time. It is around $50-60 \%$, implying that air there is saturated with respect to ice. The spuriously large relative humidity above $265 \mathrm{hpa}$ is associated with too much ice there.

Cloud fraction, temperature, and liquid and ice water contents from the model and observations are averaged over twenty days to show their mean profiles as a function of pressure (Fig. 10). Average liquid and ice water contents in the model are smaller and larger than those retrieved, respectively, although the difference between observations and the model is partly due to the way in which the values were obtained. 
Cloud amount in the model, as shown in Fig. 10, is larger than observed. The modeled cloud amount is $\sim 20 \%$ more than was observed from 800 to 250 hpa. The model air temperatures at 100 and $265 \mathrm{hpa}$ are $7.8 \mathrm{~K}$ lower and $3.5 \mathrm{~K}$ higher than observations, respectively. The simulated near-surface air temperature is $5 \mathrm{~K}$ higher than the observations. The temperature differences between the model and observations can be explained by the over prediction of cloud residue in the upper troposphere. Since cloud ice in the upper troposphere emits longwave radiation into space and absorbs upward longwave radiation from the air and land surface below, too much cloud ice near $165 \mathrm{hpa}$ decreases the temperature at $\sim 100 \mathrm{hpa}$ and increases the temperature at $265 \mathrm{hpa}$. Meanwhile, too much cloud ice in the upper troposphere also increases the downward longwave radiation, which in turn contributes partly to the over prediction of air temperature near the surface. The magnitude of the temperature error is close to that in the other models for continental clouds (e.g., Xie et al. 2005, Xu et al. 2005) and larger than that for marine clouds (Johnson et al. 2002).

Figure 11 displays the twenty-day average profiles of water vapor mixing ratio and relative humidity against pressure. The difference in the mixing ratios between the model and observations decreases from $1.1 \mathrm{~g} / \mathrm{kg}$ near the surface to zero at the tropopause. In contrast, the difference in relative humidity generally increases with height, from nearly zero at the surface to $30 \%$ at $265 \mathrm{hpa}$. The spuriously high relative humidity in the upper troposphere is associated with the over prediction of cloud ice in the upper troposphere, since cloud ice increases (or decreases) through deposition (or sublimation) when air is saturated (or unsaturated) with respect to ice. 


\section{b. Sensitivity experiments}

Experiment G00 contains $256 \times 256 \times 41$ gridpoints to test the sensitivity of simulations to domain size. This experiment shows (figure omitted) that the modeled surface precipitation agrees well with observations just as in C00. Slight surface precipitation fluctuations such as at day 1.5 are weakened. Liquid and ice water contents, relative humidity, and cloudiness resemble those shown in Figs. 7 and 9 for the control experiment $\mathrm{COO}$.

Another experiment, B00, was done using $256 \times 256 \times 41$ gridpoints and a horizontal grid size of $2 \mathrm{~km}$. The modeled surface precipitation in this experiment agrees well with observations, too. Slight surface precipitation fluctuations such as at day 1.5 are almost gone. The relative humidity from 265 to $165 \mathrm{hpa}$ is $10 \%$ smaller than in $\mathrm{C} 00$ (or G00) only from day 1.5 to 5.5 . Even though the relative humidity there is closer to observations, it is still higher than was observed. In addition, the relative humidity from 165 to 100 hpa is close to that in $\mathrm{C} 00$, much larger than observed. Corresponding to the difference between $\mathrm{B} 00$ and $\mathrm{C} 00$ in relative humidity, the cloud amount from 265 to 165 hpa in B00 is larger than in C00, implying that vertical circulations occur near 265-165 hpa and dehumidify the atmosphere there.

In addition to the preceding experiments on domain structure, two numerical experiments were done to determine the sensitivity of cloud residue to cloud microphysics. In one of them, the microphysical scheme of Rutledge and Hobbs (1984) is used, where the fall speed of graupel is smaller than that of hail in the scheme of Lin et al. (1983). The scheme is more suitable for the simulation of tropical clouds. However, 
the over prediction of cloud residue is still present in the upper troposphere, just as in $\mathrm{C} 00$.

Cloud ice sedimentation can be an important process (e.g., Wu et al. 1999; Hong et al. 2004). Experiment MO0ICE accounts for the sedimentation of cloud ice (Starr and Cox 1985). After introducing the sedimentation of cloud ice, cloud residue is improved. The difference between the model and observations in terms of relative humidity, in contrast to Fig. 9, increases slowly with time near 165 hpa. The distribution of cloud ice in the upper troposphere contains breaks in a time-pressure cross section. However, modeled relative humidity and cloud ice are still higher than observed, which is consistent with the results of Wu et al. (1999) regarding the sensitivity of cloud residue to cloud ice sedimentation.

\section{c. Dimensionality experiment (D00)}

Current MMFs mainly employ 2D CRMs for computational economy (e.g., Grabowski 2001; Khairoutdinov and Randall 2001; Chern et al. 2005). Also, Xie et al. (2005) and $\mathrm{Xu}$ et al. (2005) used four 2D CRMs to simulate two short periods from the 2000 case. Thus, the $2 \mathrm{D}$ version of the GCE model is used to simulate the case for twenty days to address dimensionality sensitivity.

The numerical experiment, referred to here as experiment D00, uses $512 \times 41$ gridpoints. Its surface precipitation (Fig. 12) shows rapid fluctuations at day $1,6.5,14.5$ and 17 in contrast to observations and the 3D model. However, after being averaged over a long period, the surface precipitation rate and its accumulated amount are close to observations. The final accumulated precipitation amount after the 20 -day integration is 
$5.6 \%$ smaller than that observed. This $5.6 \%$ difference is slightly smaller than the corresponding difference of $6.3 \%$ for the 3D model.

Time-pressure cross sections of relative humidity and ice water content for D00 are displayed in Fig. 13. When compared with Figs. 8 and 9, the figure shows that the relative humidity in the upper troposphere changes irregularly, which is quite different from the observations or from the 3D model. In addition, the distribution of ice water in the model is different from that retrieved. It also differs from the 3D model by having periods without cloud ice in the upper troposphere. Another 2D experiment with $128 \times 41$ gridpoints shows the sensitivity of cloud properties to domain size in 2D. The modeled surface precipitation is similar to that in Fig. 12 except for stronger surface precipitation fluctuations. The modeled clouds have distributions similar to those in Fig. 13 except for many fine structures in the middle troposphere. The fine structures associated with relative humidity and cloud ice in the middle troposphere are associated with the rapid fluctuation in modeled surface precipitation. The 2D simulations, in contrast to the 3D, show that fluctuations in surface precipitation are sensitive to domain size.

Figure 14 displays time-average values of relative humidity, cloud fraction, and the horizontal variance of vertical velocity and temperature against pressure for experiments $\mathrm{C} 00$ and D00 as well as the observations. The horizontal variance of vertical velocity and temperature in the upper troposphere is larger in the $2 \mathrm{D}$ experiment. This shows that the local vertical circulations in the upper troposphere are stronger in the 2D experiment than in the 3D model. Furthermore, the relative humidity in the $2 \mathrm{D}$ experiment is closer to observations on average than is the $3 \mathrm{D}$. Cloud fractions in both the $2 \mathrm{D}$ and $3 \mathrm{D}$ experiments are larger than was observed. 
The differences between the $2 \mathrm{D}$ and $3 \mathrm{D}$ simulations are attributed to the energy transfer between scales (Moeng et al. 1996) and buoyancy damping, where the latter is important near the tropopause because the energy transfer is associated with nonlinear momentum terms (e.g., Lesieur 1990) and the nonlinear terms due to convective cells are not important near the tropopause. Consider a temperature perturbation in a 3D and a $2 \mathrm{D}$ inviscid dry model. The perturbation in the 3D dry model damps down with time so that the atmosphere approaches buoyancy equilibrium while the perturbation in the 2D dry model does not (Mapes 1993; Nilsson and Emanuel 1999; Sobel and Bretherton 2000; Raymond and Zeng 2000). Therefore, when convective clouds initiate strong vertical oscillations, these oscillations persist in the 2D model but not in the $3 \mathrm{D}$ model. This results in a larger temperature variance in the upper troposphere in the $2 \mathrm{D}$ simulation ${ }^{1}$. This fundamental difference between the $2 \mathrm{D}$ and $3 \mathrm{D}$ models regarding the oscillations can explain the rapid fluctuation of surface precipitation and little water in the upper troposphere in the $2 \mathrm{D}$ simulations.

Xie et al. (2005) and Xu et al. (2005) used four 2D CRMs to simulate two short periods from the same case. Comparisons show that the 2D GCE model simulates surface precipitation intensity better than the other $2 \mathrm{D}$ models, although modeled precipitation in all models is good. Just like the other models, the 2D GCE model over-predicted cloud ice and relative humidity in the upper troposphere. Its vertical profile of relative humidity, compared to observations, is very similar to that from the Advanced Regional Prediction System at Langley Research Center (ARPS/LaRC, Xu et al. 2005). The

${ }^{1}$ The horizontal variance of temperature and vertical velocity in the upper troposphere may be influenced by numerical techniques such as the sponge layer. 
temperature error versus height in the $2 \mathrm{D}$ GCE model is similar to the other models, decreasing from $2.5 \mathrm{~K}$ at $965 \mathrm{hpa}$ to $-4 \mathrm{~K}$ at $265 \mathrm{hpa}$. The ice content in the $2 \mathrm{D}$ GCE model is closer to observations than in the other models; however, the cloud fraction in the $2 \mathrm{D}$ GCE is still larger than observed though smaller than the other models. The difference in cloud fraction between the 2D GCE and other CRMs is mainly attributed to the different definitions of cloudy area in the models.

\section{The 2002 case for summertime clouds}

\section{a. Control experiment (CO2)}

In contrast to the springtime case in the preceding section, a summertime case is studied in this section. Figure 15 displays some of the large-scale forcing data for the 2002 case, namely, large-scale horizontal temperature advection, horizontal advection of water vapor mixing ratio, and large-scale vertical velocity. Figure 2 displays the ARM surface latent and sensible heat fluxes versus time. All data start at 2030 UTC 25 May 2002 and last for 20 days. Compared with Fig. 4, Fig. 15 shows that the 2002 case has weaker large-scale forcing (e.g., large-scale vertical velocity in the planetary boundary layer). Figs. 1 and 2 show that the 2002 case has strong surface latent heat flux both in amplitude and daily average.

The control experiment for the 2002 case (C02) is a twenty-day simulation with the same parameters as C00. Figure 16 displays the observed and modeled surface precipitation versus time. The strong precipitation events are fairly well captured. Just like in the other CRMs (Xu et al. 2002), the precipitation events at day 1.5 and 17 are delayed. To test the reason for the delay in precipitation, a numerical experiment was 
made that started at day 1 with an artificial increase in water vapor in the planetary boundary layer. The results (figure omitted) show that the three precipitation events from day 1-3 are modeled well and the accumulated precipitation amount also agrees well with observations. This infers that the delay in precipitation on day 1.5 in $\mathrm{C} 02$ can be attributed to the lack of proper triggers for convective clouds.

Two spurious precipitation events, as shown in Fig. 16, appear at day 13.5 and 14.2 in contrast to observations. The precipitation event at day 14.2 is initiated by large CAPE (convective available potential energy, see Fig. 17) and further intensified by the upward large-scale motion in the middle troposphere (see Fig. 15). To test the influence of previous accumulative errors on the spurious precipitation events, a new simulation was done that started at day 13. In this experiment (figure omitted), the precipitation event at day 13.5 disappears, and the precipitation event at day 14.2 is significantly weakened but still there. In summary, experiment $\mathrm{C} 02$ and other two experiments show that convective initiation, water spin up, and large-scale forcing influence the simulation of summertime precipitation.

Figure 16 also shows that the accumulated precipitation amount in the model is smaller than the observations by $10.2 \%$. Also, the PDF for the modeled precipitation rate is similar to observations at small rainfall rates but different at high rainfall rates. In general, the model has a reasonable accumulated precipitation and rainrate PDF compared to observations.

Figure 17 displays time-pressure cross sections of observed relative humidity and cloud fraction, showing the diurnal variation of relative humidity and cloud amount in the lower troposphere. Figure 18 displays the same variables from the model. Based on these 
two figures, the model relative humidity is larger than observations, especially in the upper troposphere. A pronounced diurnal variation of low clouds exists in the model.

Twenty-day average values of water vapor mixing ratio and relative bumidity (Fig. 19) shows that observations and the model are similar in terms of water vapor mixing ratio but different for relative humidity. The modeled relative humidity is $\sim 30 \%$ higher than observed in the upper troposphere. Compared with Fig. 11, it shows that the differences between the model and observations for humidity are similar in both the 2000 and 2002 cases although the surface water vapor mixing ratio and latent heat flux are much larger for the 2002 case.

\section{b. Land surface flux experiment (L02)}

Surface fluxes are necessary in an MMF to help drive large-scale circulations over continents. Unlike the numerical experiments in the preceding sections, no observational fluxes are available for MMF. Thus, it is of interest to test the sensitivity of cloud properties to surface fluxes when the surface fluxes are provided from a land surface model. This section describes such a sensitivity experiment and its impact on the simulation of clouds and precipitation.

Experiment L02 follows the control experiment C02 except that surface fluxes as well as land surface temperature come from LIS. The LIS data are obtained after a 15-year spin-up driven by observational data with a $1 \mathrm{~km}$ horizontal resolution (see section 2.a for details). Figure 2 displays the domain-average values of the surface fluxes. The LIS fluxes have a strong diurnal signature very similar to the ARM data. The twenty-day average values of latent and sensible heat fluxes from LIS are 117.1 and $44.3 \mathrm{~W} / \mathrm{m}^{2}$, 
while the corresponding ARM data are 117.4 and $34.9 \mathrm{~W} / \mathrm{m}^{2}$, respectively. However, LIS sensible heat fluxes from day 4 to 9 are larger than ARM ones in both amplitude and daily average.

In experiment L02, LIS fluxes are assumed to be horizontally uniform. Surface precipitation characteristics (Fig. 20) are very similar to those in $\mathrm{C} 02$, but the rainrate PDF between the model and observations is different at high rainfall rate. Time-pressure cross sections of relative humidity and cloud amount from L02 are shown in Fig. 21. This and others figures on water contents (figure omitted) indicate that cloud residue is still over-predicted in the upper troposphere. However, the diurnal variation of cloud amount in the lower troposphere from day 4 to 9 is superior to $\mathrm{C} 02$. This improvement is attributed to the large LIS sensible heat flux from day 4 to 9 (see Fig. 2 for details). When the sensible heat flux increases, the upward flux of heat in the planetary boundary layer increases correspondingly, leading to the increase of the upward flux of water vapor there. Thus the surface relative humidity decreases due to the increase of air surface temperature and the decreases of water content near the surface, which increases the lifting condensation level and in turn decreases cloud amount in the lower troposphere. This connection between surface sensible heat flux and the diurnal variation of clouds in the lower troposphere (as shown in Figs. 18 and 21) is consistent with the difference in relative humidity in the planetary boundary layer between the two experiments.

The ARM and LIS fluxes come from different sources. The ARM surface fluxes used in the control experiment come from the EBBR stations, which use the Bowen ratio to partition the fluxes. There are a total of 14 EBBR stations. A grid of 0.5 degree $\times 0.5$ degree was first set up to cover the ARM SCM (single-column model) domain. Next, the 
Barnes scheme with a length scale of $80 \mathrm{~km}$ was used to fill all the boxes. These 0.5 degree $\mathrm{x} 0.5$ degree boxes within the SCM domain were then averaged to get the areaaveraged surface fluxes. Based on this procedure for the ARM surface flux data, it is inferred that some uncertainty is introduced into the ARM-averaged fluxes due to the small representative scale of land variables. In contrast, the LIS fluxes were obtained from a land surface model that was driven with observational data of $1 \mathrm{~km}$-resolution (see section 2.a for details). Although the LIS fluxes at a point are not as accurate as the ARM fluxes, their fine resolution may lead to better area-averaged fluxes than those from "sparse" observational stations. However, this topic remains open and further comparisons between the two kinds of surface flux data are needed.

\section{Discussions}

Thermodynamics dominate atmospheric circulations on sufficiently large scales (Neelin and Held 1987; Emanuel 1995, 1999; Raymond 1995, 2000; Raymond and Zeng 2000; Zeng et al. 2005). Consequently, large-scale vertical circulations are sensitive to atmospheric radiative cooling rate and the surface fluxes from the underlying surface (e.g., Zeng et al. 2005). Due to the significant influence of clouds on atmospheric radiation, the present paper compares clouds and surface fluxes in long-term simulations with observational data for the evaluation of CRMs in MMFs.

Two twenty-day, continental midlatitude periods are simulated with the 3D GCE model and surface fluxes obtained from either observations or LIS. Observational largescale forcing data from the ARM project are used to drive the model. Modeling results 
are compared with the observed cloud data obtained from the ARM project, showing the benefits and bias of long-term CRM simulations.

\section{a. Cloud residue}

Modeled cloud residue (i.e., cloud water, ice, and water vapor) in long-term integrations is compared with observations from middle latitudes. Modeled cloud ice has

a much higher frequency of occurrence than observations in the upper troposphere. Correspondingly, modeled relative humidity is much larger than observations there. A similar bias in cloud residue was evident in a 7-day simulation of GATE cloud systems (Grabowski et al. 1998). In addition, cloud fraction in the model is larger than observations. Modeled water and ice are smaller and larger than those retrieved, respectively, which is consistent with $\mathrm{Xu}$ et al. (2005) on the basis of $2 \mathrm{D}$ CRM simulations.

Clouds, as shown in the sensitivity experiments, are influenced by many factors such as cloud microphysics, surface fluxes, dimensionality, and domain size. The over prediction of cloud residue may have multiple origins such as the periodic boundary condition as proposed by Grabowski et al. (1998) and Wu et al. (1998).

\section{b. Dimensionality}

Two-dimensional numerical experiments are performed to test the sensitivity of clouds and precipitation to dimensionality. As compared with observations, the 3D model produces better simulations than the $2 \mathrm{D}$ one. The $2 \mathrm{D}$ model has rapid fluctuations in surface precipitation. These fluctuations decrease when the number of domain gridpoints is increased. Grabowski et al. (1998) simulated oceanic clouds in the Tropics with both a 
2D and 3D CRM and found the similar rapid fluctuations of precipitation in their $2 \mathrm{D}$ simulations in contrast to their 3D simulation.

Relative humidity in the upper troposphere in the $2 \mathrm{D}$ model is higher than observations although the relative humidity there is closer to observations than in the $3 \mathrm{D}$ model. Modeled cloud ice in the upper troposphere covers a wider area than observations. The over prediction of cloud residue in the upper troposphere was also found in $2 \mathrm{D}$ simulations from four CRMs that were part of the ARM model inter-comparison (Xie et al. 2005; Xu et al. 2005). A similar over prediction of cloud residue occured in a 39-day 2D simulation of TOGA COARE cloud systems (Wu et al. 1998). The vertical profile of relative humidity from the $2 \mathrm{D}$ GCE in comparison with observations is very similar to that from ARPS/LaRC (Xu et al. 2005).

Clouds and precipitation are sensitive to dimensionality because of the difference in buoyancy damping and energy transfer between scales between $2 \mathrm{D}$ and $3 \mathrm{D}$ models. Temperature perturbations in the 3D model damp down due to gravity waves but not in the $2 \mathrm{D}$ model $^{2}$. Thus, oscillations in the $2 \mathrm{D}$ model, once generated by clouds, persist longer than in the $3 \mathrm{D}$ model, leading to cloud ice deposition in the upper troposphere and in turn dehumidification there after ice falls out.

This evaluation of long-term CRM simulations provides a perspective on current MMFs. The over prediction of cloud residue (especially cloud ice) in the upper

\footnotetext{
${ }^{2}$ Readers interested in the difference in buoyancy damping between $2 \mathrm{D}$ and $3 \mathrm{D}$ models can start with a linear model for an inviscid and irrotational dry atmosphere. Once a temperature perturbation is imposed in the atmosphere, as shown by analytical solutions, it will have a different tendency in amplitude due to dimensionality.
} 
troposphere, for example, partly explain "Red Spots" (or excessive precipitation) in the Tropics and over-active Madden-Julian oscillations in the current MMFs (e.g., Khairoutdinov and Randall 2001; Khairoutdinov et al. 2005; Chern et al. 2005), since clouds modulate radiation (e.g., Albrecht and Cox 1975; Grabowski et al. 1999) which in turn change large-scale circulations (e.g., Zeng et al. 2005) and consequently precipitation (e.g., Raymond and Zeng 2005) in a positive feedback (e.g., Raymond 2000; Raymond and Zeng 2000).

\section{c. Comparison with previous studies}

Several long-term CRM modeling studies have been performed recently, using the models with large-scale forcing. These previous studies can be compared to the present one to evaluate the sensitivity of cloud residue to model structure.

Wu et al. (1998), using the Clark-Hall cloud model (Clark et al. 1996), performed 2D simulations of TOGA-COARE cloud systems for 39 days. They found that ice and liquid water contents were too large. Grabowski et al. (1998) noticed similar results in a 7-day simulation of GATE cloud systems from their 2D and 3D simulations. Wu et al. (1999) reported the sensitivity of cloud ice in the upper troposphere to cloud microphysics (or the sedimentation of cloud ice). They showed that the over prediction of relative humidity is improved with the increase of cloud ice sedimentation, but is still there. Similar results were obtained from other CRMs (Xu et al. 2002). The present results agree with the previous ones on the over prediction of cloud residue in the upper troposphere.

Grabowski et al. (1998) and Khairoutdinov and Randall (2003) did long-term simulations, in contrast to observations, for dimensionality sensitivity. Grabowski et al. (1998) pointed out that 2D simulations produced a much higher temporal variability of 
domain-averaged quantities in comparison to 3D simulations. The present simulations also support this modeling phenomenon. Moeng et al. (1996) showed a significant difference in horizontal variance of variables between the 2D and 3D simulations in the convective boundary layer. Khairoutdinov and Randall (2003) found that significant differences between 2D and 3D simulations had in temperature and vertical velocity variance, especially near the tropopause. They further inferred that a temperature perturbation in $2 \mathrm{D}$ does not decay with distance from its source as fast as in $3 \mathrm{D}$. In the present study, the difference in vertical velocity and temperature variance between $2 \mathrm{D}$ and 3D simulations is also evident. These differences in variance, especially in the upper troposphere, can be explained by the difference in model buoyancy damping.

It is not surprising that strong, local vertical circulations can influence cloud residue in the upper troposphere. Suppose that the air in the upper troposphere is saturated with respect to ice and that the ice falls out immediately as precipitation once deposition occurs. When strong vertical oscillations (or gravity waves) appear in the upper troposphere, the air is dehumidified, which shows how local vertical circulations can influence cloud residue. With this idealized case for perspective, it is not difficult to understand how differences in the present $2 \mathrm{D}$ and $3 \mathrm{D}$ simulations can impact cloud residue in the upper troposphere.

\section{Summary}

Two twenty-day, continental midlatitude cases are simulated with a CRM and compared with ARM data to evaluate the benefit and bias of CRMs in MMFs. Modeled surface precipitation is compared with observations first and then cloud residue is 
compared, because surface precipitation and cloud residue are associated with cloud growth and decay, respectively, to some extent.

All numerical experiments in the present paper output reasonable surface precipitation, as have other CRMs (e.g., Grabowski et al. 1998; Khairoutdinov and Randall 2003; Xie et al. 2002, 2005; Xu et al. 2002, 2005). Well-simulated surface precipitation implies that CRMs properly represent the upward flux of water vapor associated with cloud growth. However, all of the numerical experiments over-predict ice and relative humidity in the upper troposphere, which alters the vertical profile of temperature through atmospheric radiation. Such over prediction appears in other CRMs too (e.g., Xie et al. 2005; Xu et al. 2005) and needs to be addressed as a high priority for long-term CRM simulations.

Special attention is given to the sensitivity of cloud properties to dimensionality in the present paper. Numerical results show that surface precipitation fluctuates more rapidly in the 2D CRM than in the 3D CRM. The 2D CRM also has less cloud residue in the upper troposphere. This sensitivity of simulated cloud properties can be explained by the difference in buoyancy damping between the $2 \mathrm{D}$ and the $3 \mathrm{D}$ models.

Surface fluxes from LIS, a land data assimilation system, are compared with the ARM data. The LIS latent heat flux is close to observations, but its sensible heat flux is larger than observations for a period. When LIS surface flux data replace ARM data in the CRM simulations, similar results are obtained except that LIS brings about a better simulation of diurnal cloud variation in the lower troposphere. This work suggests that ARM and LIS surface flux data should be compared further with more cases in the future. 
Acknowledgments: The GCE model is mainly supported by the NASA Headquarters Atmospheric Dynamics and Thermodynamics Program and the NASA Tropical Rainfall Measuring Mission (TRMM). The authors are grateful to Dr. R. Kakar at NASA headquarters for his support of this research. The research was also supported by the Office of Science (BER), U. S. Department of Energy, Interagency Agreement No. DEAI02-04ER63755 and NASA AIST. Additional support is provided by NSF and the DOE ARM program to the Stony Brook University. Dr. Xie, working at LLNL, was supported under the auspices of the U. S. Department of Energy (DOE) Office of Science, Biological and Environmental Research by the University of California Lawrence Livermore National Laboratory under contract W-7405-Eng-48.

The authors acknowledge NASA Goddard Space Flight Center for computer time used in this research. They appreciate Dr. Yali Luo for providing the code to compute radar reflectivity from model mixing ratios of water species. 


\section{References}

Ackerman, T. P., and G. M. Stokes, 2003: The Atmospheric Radiation Measurement Program. Phys. Today, 56, 38-44.

Albrecht, B. and S. K. Cox, 1975: The large-scale response of the tropical atmosphere to cloud-modulated infrared heating. J. Atmos. Sci., 32, 16-24.

Cess, R. D., and Coauthors, 1990: Intercomparison and interpretation of climate feedback processes in 19 atmospheric general model. J. Geophys. Res., 95, 16,601-16,615.

Chern, J.-D., W.-K. Tao and R. Atlas, 2005: Preliminary results of the Goddard Multiscale Modeling Framework. ARM CPM WG 2005 Fall Meeting, Stony Brook, New York, Oct. 12-13, 2005.

Clark, T. L., W. D. Hall, and J. L. Coen, 1996: Source code documentation for the ClarkHall cloud-scale model: Code version G3CH01. NCAR Tech. Note NCAR/TN426+STR, 137pp. [Available from NCAR Information Service, P.O. Box 3000, Boulder, CO 80307.]

Clothiaux, E. E., and coauthors, 2000: Objective determination of cloud heights and radar reflectivities using a combination of active remote sensors at the ARM CART sites. J. Appl. Meteor., 39, 645-665.

Cosgrove, B. A., D. Lohmann, K. E. Mitchell, P. R. Houser, E. F. Wood, J. Schaake, A. Robock, C. Marshall, J. Sheffield, L. Luo, Q. Duan, R. T. Pinker, J. D. Tarpley, R. W. Higgins, and J. Meng (2003), Real-time and retrospective forcing in the North American Land Data Assimilation System (NLDAS) project. J. Geophys. Res., 108(D22), 8842. 
Dong, X., and G. G. Mace, 2003: Profiles of low-level stratus cloud microphysics deduced from ground-based measurements. J. Atmos. Oceanic Tech., 20, 42-53.

Donner, L. J., C. J. Seman and R. S. Hemler, 1999: Three-dimensional cloud-system modeling of GATE convection. J. Atmos. Sci., 56; 1885-1912.

Emanuel, K. A., 1995: The behavior of a simple hurricane model using a convective scheme based on subcloud-layer entropy equilibrium. J. Atmos. Sci., 52, 39603968.

Emanuel, K. A., 1999: Thermodynamic control of hurricane intensity. Nature, 401, 665669.

Emanuel, K. A., and D. J. Raymond, 1993: The representation of cumulus convection in numerical models. Meteor. Monog., 46, 246.

Grabowski, W. W., 2001: Coupling cloud processes with the large-scale dynamics using the cloud-resolving convection parameterization (CRCP). J. Atmos. Sci., 58, 978997.

Grabowski, W. W., X. Wu, M. W. Moncrieff, and D. Hall, 1998: Cloud-resolving modeling of cloud systems during Phase III of GATE. Part II: Effects of resolution and the third spatial dimension. J. Atmos. Sci., 55, 3264-3282.

Grabowski, W. W., X. Wu, and M. W. Moncrieff, 1999: Cloud-resolving modeling of tropical cloud systems during Phase III of GATE. Part III: Effects of cloud microphysics. J. Atmos. Sci., 56, 2384-2402.

Hansen, M.C., DeFries, R.S., Townshend, J.R.G., and Soblberg, R., 2005: Global land cover classification at $1 \mathrm{~km}$ spatial resolution using a classification tree approach. International Journal of Remote Sensing, (in press). 
Heymsfield, A. J., and L. J. Donner, 1990: A scheme for parameterizing ice-cloud water content in general circulation models. J. Atmos. Sci., 47, 1865-1877.

Heymsfield, A. J., and J. Iaquinta, 2000: Cirrus crystal terminal velocities. J. Atmos. Sci., $57,916-938$.

Hong, S.-Y., J. Dudhia, and S.-H. Chen, 2004: A revised approach to ice-microphysical processes for the bulk parameterization of cloud and precipitation. Mon. Wea. Rev., $132,103-120$.

Johnson, D. E., W.-K. Tao, J. Simpson, and C.-H. Sui, 2002: A study of the response of deep tropical clouds to large-scale thermodynamic forcing. Part I: Modeling strategies and simulations of TOGA COARE convective systems. J. Atmos. Sci., $59,3492-3518$

Khairoutdinov, M. F., and D. A. Randall, 2001: A cloud-resolving model as a cloud parameterization in the NCAR Communicate Climate System Model: Preliminary Results. Geophys. Res. Lett., 28, 3617-3620.

Khairoutdinov, M. F., and D. A. Randall, 2003: Cloud resolving modeling of the ARM summer 1997 IOP: Model formulation, results, uncertainties, and sensitivities. $J$. Atmos. Sci., 60, 607-625.

Khairoutdinov, M. F., D. A. Randall, and C. DeMott, 2005: Simulation of the atmospheric general circulation using a cloud-resolving model as a superparameterization of physical processes. J. Atmos. Sci., 62, 2136-2154.

Klemp, J. B. and R. B. Wilhelmson, 1978: The simulation of three-dimensional convective storm dynamics. J. Atmos. Sci., 35, 1070-1096. 
Krueger, S. K., 1988: Numerical simulation of tropical cumulus clouds and their interaction with the subcloud layer. J. Atmos. Sci., 45, 2221-2250.

Kumar, S. V., C. D. Peters-Lidard, Y. Tian, P. R. Houser, J. Geiger, S. Olden, L. Lighty, J. L. Eastman, B. Doty, P. Dirmeyer, J. Adams, K. Mitchell, E. F. Wood and J. Sheffield, 2004. Land Information System - An Interoperable Framework for High Resolution Land Surface Modeling. Environmental Modeling \& Software, (in press).

Lesieur, M., 1990, Turbulence in fluids, 2nd ed., Kluwer Academic Publishers, Netherlands, 412pp.

Lin, Y.-L., R. D. Farley, and H. D. Orville, 1983: Bulk parameterization of the snow field in a cloud model. J. Clim. Appl. Met., 22, 1065-1092.

Lipps F. B. and R. S. Hemler, 1986: Numerical simulation of deep tropical convection associated with large-scale convergence. J. Atmos. Sci., 43, 1796-1816.

Luo, Y., S. K. Krueger, G. G. Mace, and K.-M. Xu, 2003: Cirrus cloud properties from a cloud-resolving model simulation compared to cloud radar observations. J. Atmos. Sci., 60, 510-525.

Mapes, B. E., 1993: Gregarious tropical convection. J. Atmos. Sci., 50, 2026-2037.

Miller, M. A., K. L. Johnson, D. T. Troyan, E. E. Clothiaux, E. J. Mlawer, and G. G. Mace, 2003: ARM value-added cloud products: Description and status. Thirteenth ARM Science Team Meeting Proceedings, U. S. Dept of Energy, Washington, D. C. (Available from http://www.arm.gov/publications/proceedings/conf13/extended_abs/millerma.pdf.) 
Moeng, C.-H., and Coauthors, 1996: Simulation of a stratocumulus-topped planetary boundary layer: Intercomparison among different numerical codes. Bull. Amer. Meteor. Soc., 77, 261-278.

Moncrieff, M. W., S. K. Krueger, D. Gregory, J.-L. Redelsperger, and W.-K. Tao, 1997:

GEWEX Cloud System Study (GCSS) Working Group 4: Precipitating convective cloud systems. Bull. Am. Meteor. Soc., 78, 831-845.

Neelin, J. D., and I. M. Held, 1987: Modeling tropical convergence based on the moist static energy budget. Mon. Wea. Rev., 115, 3-12.

Nilsson, J. and K. A. Emanuel, 1999: Equilibrium atmosphere of a two-column radiative convective model. Quart. J. Roy. Meteor. Soc., 125, 2239-2264.

Randall, D., M. Khairoutdinov, A. Arakawa, and W. Grabowski, 2003: Breaking the cloud parameterization deadlock. Bull. Ameri. Meteor. Soc., 84, 1547-1564.

Raymond, D. J., 1995: Regulation of moist convection over the west Pacific warm pool. J. Atmos. Sci., 52, 3945-3959.

Raymond, D. J., 2000: The Hadley circulation as a radiative-convective instability. $J$. Atmos. Sci., 57, 1286-1297.

Raymond, D. J. and X. Zeng, 2000: Instability and large-scale circulations in a twocolumn model of the tropical troposphere. Quart. J. Roy. Meteor. Soc., 126, $3117-$ 3135.

Raymond, D. J. and X. Zeng, 2005: Modeling tropical atmospheric convection in the context of the weak temperature gradient approximation. Quart. J. Roy. Meteor. Soc., 131, 1301-1320. 
Rutledge, S. A. and P. V. Hobbs, 1984: The mesoscale and microscale structure and organization of clouds and precipitation in mid-latitude clouds. Part XII: A diagnostic modeling study of precipitation development in narrow cold frontal rainbands. J. Atmos. Sci., 41, 2949-2972.

Simpson, J., and W.-K. Tao, 1993: The Goddard Cumulus Ensemble model. Part II: Applications for studying cloud precipitating processes and for NASA TRMM. Terr. Atmos. Oceanic Sci., 4, 73-116.

Smolarkiewicz, P. K., and W. W. Grabowski, 1990: The multidimensional positive advection transport algorithm: non-oscillatory option. J. Comp. Phys., 86, 355375.

Sobel, A. H. and C. S. Bretherton, 2000: Modeling tropical precipitation in a single column. J. Climate, 13, 4378-4392.

Soil Survey Staff, Natural Resources Conservation Service, United States Department of Agriculture. State Soil Geographic (STATSGO) Database for State (available from http://www.ncgc.nrcs.usda.gov/products/datasets/statsgo/index.html).

Soong, S.-T. and Y. Ogura, 1980: Response of tradewind cumuli to large-scale processes. J. Atmos. Sci., 37, 2035-2050.

Starr, D. O., and S. K. Cox, 1985: Cirrus clouds. Part I: cirrus cloud model. J. Atmos. Sci., 42, 2663-2681.

Tao, W.-K. and S.-T. Soong, 1986: A study of the response of deep tropical clouds to mesoscale processes. Three-dimensional numerical experiments. J. Atmos. Sci., 43, 2653-2676. 
Tao, W.-K., J. Simpson, and S.-T. Soong, 1987: Statistical properties of a cloud ensemble: A numerical study. J. Atmos. Sci., 44, 3175-3187.

Tao, W.-K. and J. Simpson, 1993: The Goddard Cumulus Ensemble model. Part I: Model description. Terr. Atmos. Oceanic Sci., 4, 19-54.

Tao, W.-K., S. Lang, J. Simpson, C.-H. Sui, B. Ferrier, and M.-D. Chou, 1996: Mechanism of cloud-radiation interaction in the tropics and mid-latitude. $J$. Atmos. Sci., 53, 2624-2651.

Tao, W.-K., 2003: Goddard cumulus ensemble (GCE) model: Application for understanding precipitating processes. Cloud systems, hurricanes, and the Tropical Rainfall Measuring Mission (TRMM). W.-K. Tao and R. Adler Ed., Meteor. Monogr., 29, 107-138

Tao, W.-K., J. Simpson, D. Baker, S. Braun, M.-D. Chou, B. Ferrier, D. Johnson, A. Khain, S. Lang, B. Lynn, C.-L. Shie, D. Starr, C.-H. Sui, Y. Wang and P. Wetzel, 2003: Microphysics, radiation and surface processes in the Goddard Cumulus Ensemble (GCE) model. Meteor. Atmos. Phys., 82, 97-137.

Tompkins A. M. and G. C. Craig, 1998: Radiative-convective equilibrium in a threedimensional cloud ensemble model. Quart. J. Roy. Meteor. Soc., 124, 2073-2098.

Wakimoto, R. M., H. V. Murphey, R. G. Fovell, and W.-C. Lee, 2004: Mantle echoes associated with deep convection: observations and numerical simulations. Mon. Wea. Rev., 132, 1701-1720.

Weckwerth, T. M., and Coauthors, 2004: An overview of the International $\mathrm{H}_{2} \mathrm{O}$ Project (IHOP_2002) and some preliminary highlights. Bull. Amer. Meteor. Soc., 85, 253277. 
Wu, X., W. W. Grabowski, and M. W. Moncrieff, 1998: Long-tern behavior of cloud systems in TOGA COARE and their interactions with radiative and surface processes. Part I: Two-dimensional modeling study. J. Atmos. Sci., 55, 26932714.

Wu, X., W. D. Hall, W. W. Grabowski, M. W. Moncrieff, W. D. Collins, and J. T. Kiehl, 1999: Long-tern behavior of cloud systems in TOGA COARE and their interactions with radiative and surface processes. Part II: Effects of ice microphysics on cloud-radiation interaction. J. Atmos. Sci., 56, 3177-3195.

Xie, S., and coauthors, 2002: Intercomparison and evaluation of cumulus parameterization under summertime midlatitude continental conditions. Quart. $J$. Roy. Soc., 128, 1095-1135.

Xie, S., M. H. Zhang, M. Branson, R. T. Cederwall, A. D. Del Genio, Z. A. Eitzen, S. J. Ghan, S. F. Iacobellis, K. L. Johnson, M. Khairoutdinov, S. A. Klein, S. K. Krueger, W. Lin, U. Lohmann, M. A. Miller, D. A. Randall, R. C. J. Somerville, Y. C. Sud, G. K. Walker, A. Wolf, X. Wu, K.-M. Xu, J. J. Yio, G. Zhang and J. Zhang, 2005: Simulations of midlatitude frontal clouds by single-column and cloud-resolving models during the Atmospheric Radiation Measurement March 2000 cloud intensive operational period. J. Geophys. Res., 110. D15S03, doi:10.1029/2004JD005119.

Xu, K.-M., and D. A. Randall, 1996: Explicit simulation of cumulus ensembles with the GATE Phase III data: Comparison with observations. J. Atmos. Sci., 53, 37093736. 
$\mathrm{Xu}, \mathrm{K} . \mathrm{M}$, and coauthors, 2002: An intercomparison of cloud-resolving models with the Atmospheric Radiation Measurement summer 1997 IOP data. Quart. J. Roy. Meteor. Soc., 128, 593-624.

Xu, K.-M., M. H. Zhang, Z. A. Eitzen, S. J. Ghan, S. A. Klein, X. Wu, S. Xie, M. Branson, A. D. Del Genio, S. F. Tacobellis, M. Khairoutdinov, W. Lin, U. Lohmann, D. A. Randall, R. C. J. Somerville, Y. C. Sud, G. K. Walker, A. Wolf, J. J. Yio and J. Zhang, 2005: Modeling springtime shallow frontal clouds with cloud-resolving and single-column models. J. Geophys. Res., 110. D15S04, doi: $10.1029 / 2004 J D 005153$.

Zeng, X., W.-K. Tao and J. Simpson, 2005: An equation for moist entropy in a precipitating and icy atmosphere. J. Atmos. Sci. 62, 4293-4309.

Zhang, M. H. and J. L. Lin, 1997: Constrained variational analysis of sounding data bases on column-integrated budgets of mass, heat, moisture, and momentum: Approach and application to ARM measurements. J. Atmos. Sci., 54, 1503-1524.

Zhang, M. H., J. L. Lin, R. T. Cederwall, J. J. Yio, and S. C. Xie, 2001: Objective analysis of ARM IOP Data: Method and sensitivity. Mon. Wea. Rev., 129, 295311.

Zhang, M. H., W. Y. Lin, S. A. Klein, J. T. Bacmeister, S. Bony, R. T. Cederwall, A. D. Del Genio, J. J. Hack, N. G. Loeb, U. Lohmann, P. Minnis, I. Musat, R. Pincus, P. Stier, M. J. Suarez, M. J. Webb, J. B. Wu, S. C. Xie, M.-S. Yao and J. H. Zhang, 2005: Compring clouds and their seasonal variations in 10 atmospheric general circulation models with satellite measurement. J. Geophys. Res., 110. D15S02, doi:10.1029/2004JD005021. 


\section{Caption}

Figure 1 Time series of surface fluxes for the 2000 case. The data start at 1730 UTC 1 March 2000. Solid and dashed lines denote latent and sensible heat fluxes, respectively. Thick lines display daily-averaged values.

Figure 2 Time series of surface fluxes for the 2002 case. All data start at 2030 UTC 25 May 2002. Solid and dashed thin lines represent the surface fluxes from the ARM observations and LIS land data assimilation system, respectively. Thick lines represent corresponding daily-averaged values.

Figure 3 Horizontal distribution of the surface fluxes at day 1 obtained from LIS.

Figure 4 Time-pressure cross sections of large-scale horizontal temperature advection (upper), horizontal advection of water vapor mixing ratio (middle), and large-scale vertical velocity (lower pane). Data start at 1730 UTC 1 March 2000. Shaded areas indicate positive values; dashed and solid lines represent negative and positive valued contour levels, respectively.

Figure 5 Surface precipitation for the spring 2000 period. Green and black solid lines represent observations and control experiment $\mathrm{C} 00$, respectively. Surface precipitation rate and accumulated rainfall are shown in the upper and middle panes, respectively. The PDF of surface precipitation is shown in the lower pane.

Figure 6 Time-pressure cross sections of retrieved liquid and ice water contents starting from 1730 UTC 1 March 2000.

Figure 7 Time-pressure cross sections of liquid and ice water contents obtained from the control experiment $\mathrm{C} 00$ for the spring 2000 period. 
Figure 8 Time-pressure cross sections of observed relative humidity and cloud fraction starting from 1730 UTC 1 March 2000. In the upper part, shaded areas indicate a relative humidity of more than 50\%; dashed and solid lines represent the contour levels with relative humidity smaller and larger than $50 \%$, respectively.

Figure 9 Time-pressure cross sections of relative humidity and cloud fraction from the control experiment $\mathrm{C} 00$ for the spring 2000 period. In the upper part, shaded areas indicate a relative humidity of more than 50\%; dashed and solid lines represent the contour levels with relative humidity smaller and larger than $50 \%$, respectively.

Figure 10 Twenty-day mean profiles of liquid and ice water content, cloud fraction, and air temperature difference between the model and observations against pressure in the 2000 case. Thick and thin lines represent variables from observations and experiment C00, respectively.

Figure 11 Same as Fig. 10 except for relative humidity and the mixing ratio of water vapor.

Figure 12 Same as Fig. 5 except for the experiment D00 (a 2D numerical experiment for the 2000 case).

Figure 13 Time-pressure cross-sections of relative humidity and ice water content in experiment D00 (a 2D numerical experiment for the 2000 case).

Figure 14 Twenty-day mean profiles of relative humidity, cloud fraction, vertical velocity variance, and temperature variance against pressure in the 2000 case. Thick lines represent observed variables; thin lines variables from experiment $\mathrm{C} 00$; and thin dashed lines variables from experiment D00. 
Figure 15 Same as Fig. 4 except for the 2002 case. Data start at 2030 UTC 25 May 2002.

Figure 16 Same as Fig. 5 except for the 2002 case. The numerical experiment is $\mathrm{C} 02$.

Figure 17 Same as Fig. 8 except for the 2002 case.

Figure 18 Same as Fig. 9 except for the 2002 case. Data are from the control experiment $\mathrm{C} 02$.

Figure 19 Same as Fig. 11 except for the 2002 case. The numerical experiment is C02.

Figure 20 Same as Fig. 16 except for the 2002 case and experiment L02.

Figure 21 Same as Fig. 18 except for the 2002 case and experiment L02. 
Table 1 List of Numerical Experiments

\begin{tabular}{|c|c|c|c|c|c|c|}
\hline $\begin{array}{l}\text { Experiment } \\
\text { Name }\end{array}$ & Period & $\begin{array}{l}\text { Dimen } \\
\text {-sion }\end{array}$ & $\begin{array}{l}\text { Grid } \\
\text { Size }\end{array}$ & Gridpoint & $\begin{array}{l}\text { Surface } \\
\text { Flux }\end{array}$ & Comments \\
\hline $\mathrm{COO}$ & $3 / 1-3 / 20,2000$ & 3 & $1 \mathrm{~km}$ & $128 \times 128 \times 41$ & ARM & $\begin{array}{l}\text { control run for case } \\
2000\end{array}$ \\
\hline $\mathrm{B} 00$ & $3 / 1-3 / 20,2000$ & 3 & $2 \mathrm{~km}$ & $256 \times 256 \times 41$ & ARM & big domain \\
\hline G00 & $3 / 1-3 / 20,2000$ & 3 & $1 \mathrm{~km}$ & $256 \times 256 \times 41$ & ARM & spatial grid size \\
\hline MOOICE & $3 / 1-3 / 20,2000$ & 3 & $1 \mathrm{~km}$ & $128 \times 128 \times 41$ & ARM & $\begin{array}{l}\text { run with } \\
\text { sedimentation of } \\
\text { cloud ice }\end{array}$ \\
\hline M00RH & $3 / 1-3 / 20,2000$ & 3 & $1 \mathrm{~km}$ & $128 \times 128 \times 41$ & ARM & $\begin{array}{l}\text { run with the scheme } \\
\text { of Rutledge and } \\
\text { Hobbs (1984) }\end{array}$ \\
\hline D00 & $3 / 1-3 / 20,2000$ & 2 & $1 \mathrm{~km}$ & $512 \times 41$ & ARM & $\begin{array}{l}\text { dimensionality } \\
\text { sensitivity }\end{array}$ \\
\hline $\mathrm{C} 02$ & $5 / 25-6 / 13,2002$ & 3 & $1 \mathrm{~km}$ & $128 \times 128 \times 41$ & ARM & $\begin{array}{l}\text { control run for case } \\
2002\end{array}$ \\
\hline L02 & $5 / 25-6 / 13,2002$ & 3 & $1 \mathrm{~km}$ & $128 \times 128 \times 41$ & LIS & $\begin{array}{l}\text { land surface flux } \\
\text { sensitivity }\end{array}$ \\
\hline
\end{tabular}




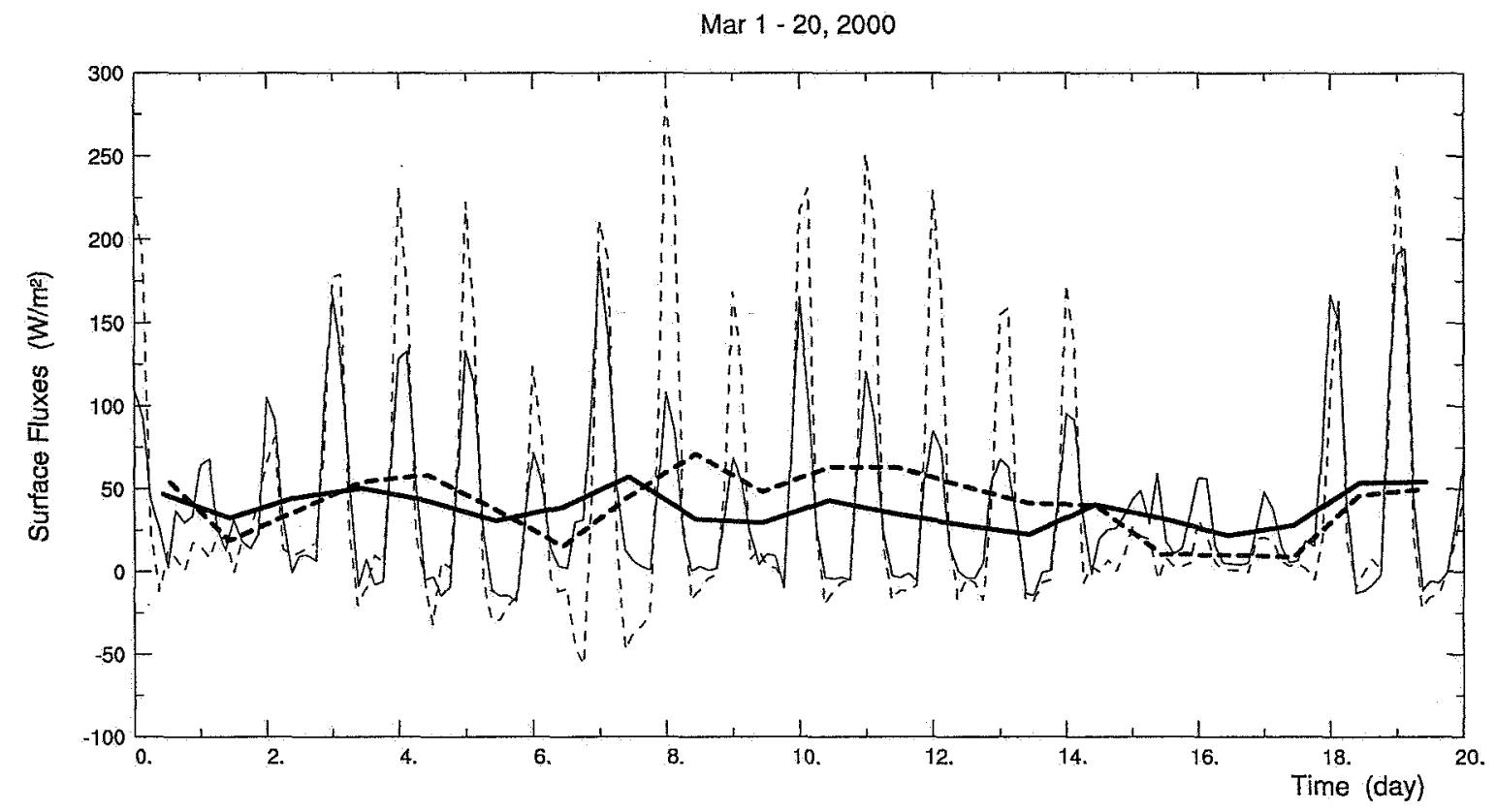

Figure 1 Time series of surface fluxes for the 2000 case. The data start at 1730 UTC 1 March 2000. Solid and dashed lines denote latent and sensible heat fluxes, respectively. Thick lines display daily-averaged values. 

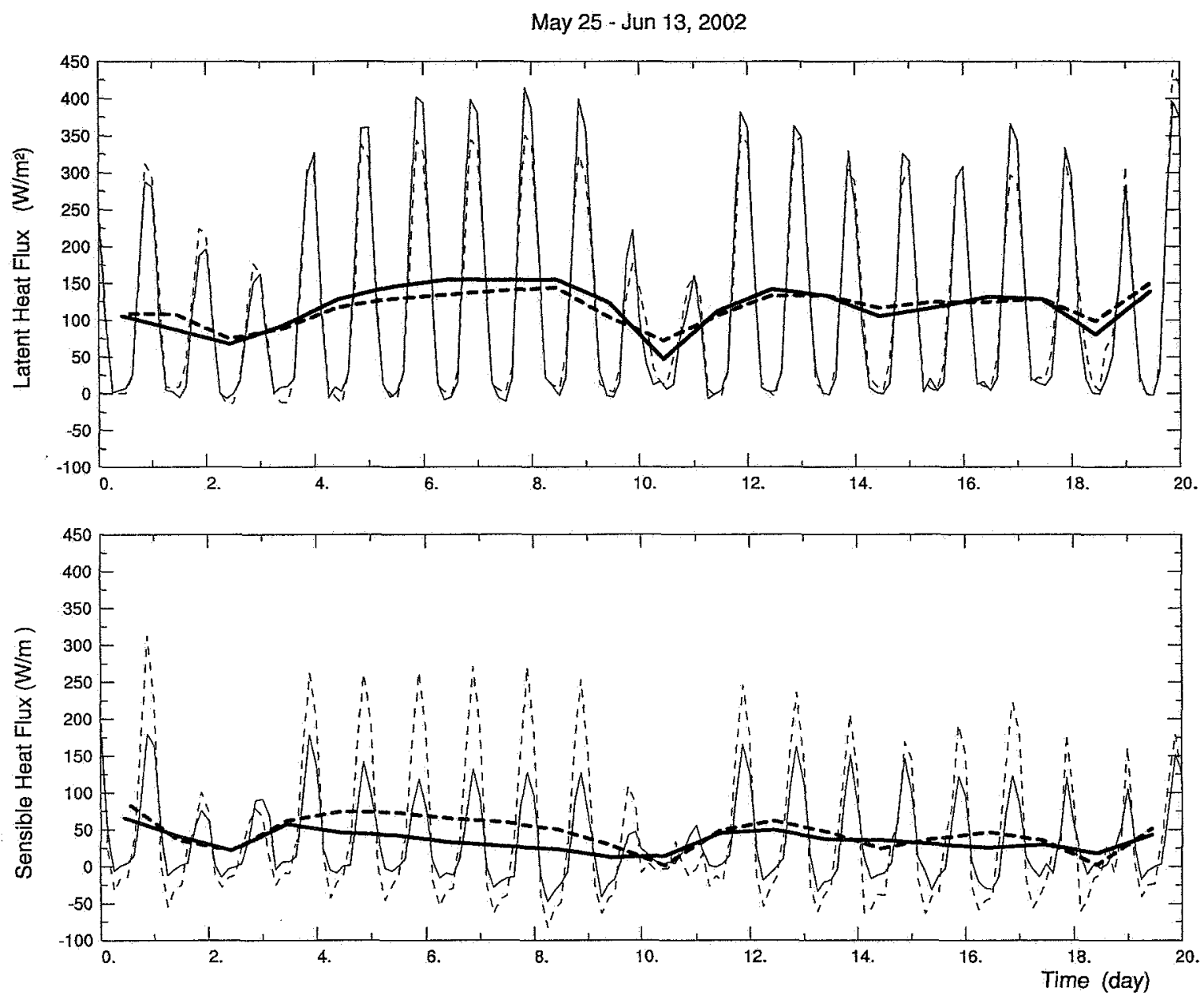

Figure 2 Time series of surface fluxes for the 2002 case. All data start at 2030 UTC 25 May 2002. Solid and dashed thin lines represent the surface fluxes from the ARM observations and LIS land data assimilation system, respectively. Thick lines represent corresponding daily-averaged values. 


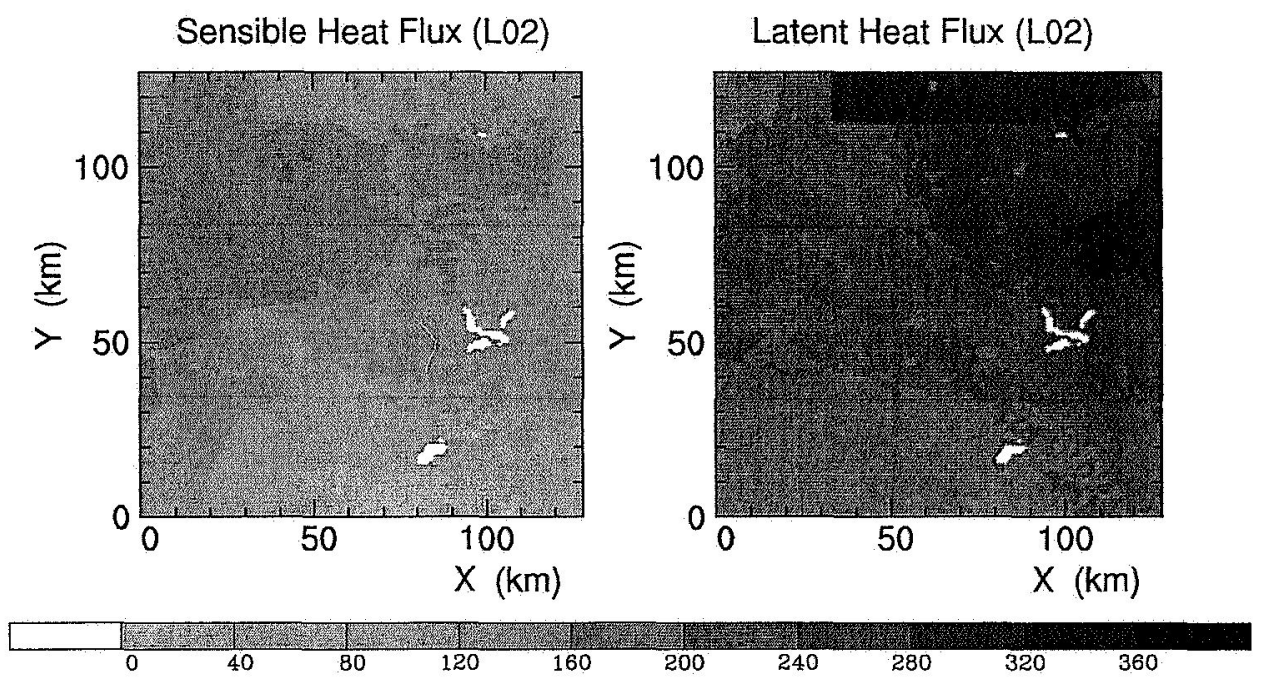

Figure 3 Horizontal distribution of the surface fluxes at day 1 obtained from LIS. 

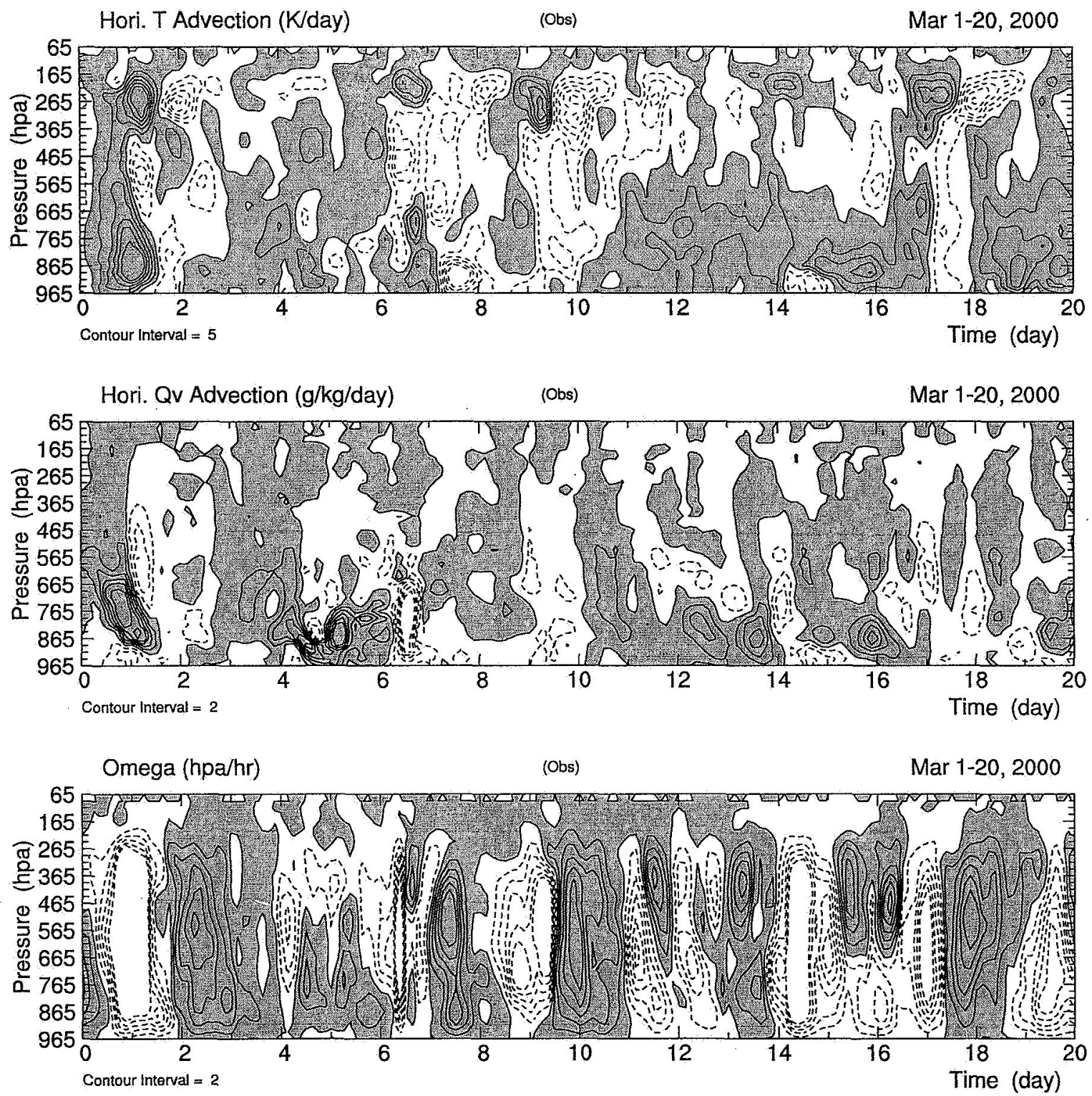

Figure 4 Time-pressure cross sections of large-scale horizontal temperature advection (upper), horizontal advection of water vapor mixing ratio (middle), and large-scale vertical velocity (lower pane). Data start at 1730 UTC 1 March 2000. Shaded areas indicate positive values; dashed and solid lines represent negative and positive valued contour levels, respectively. 

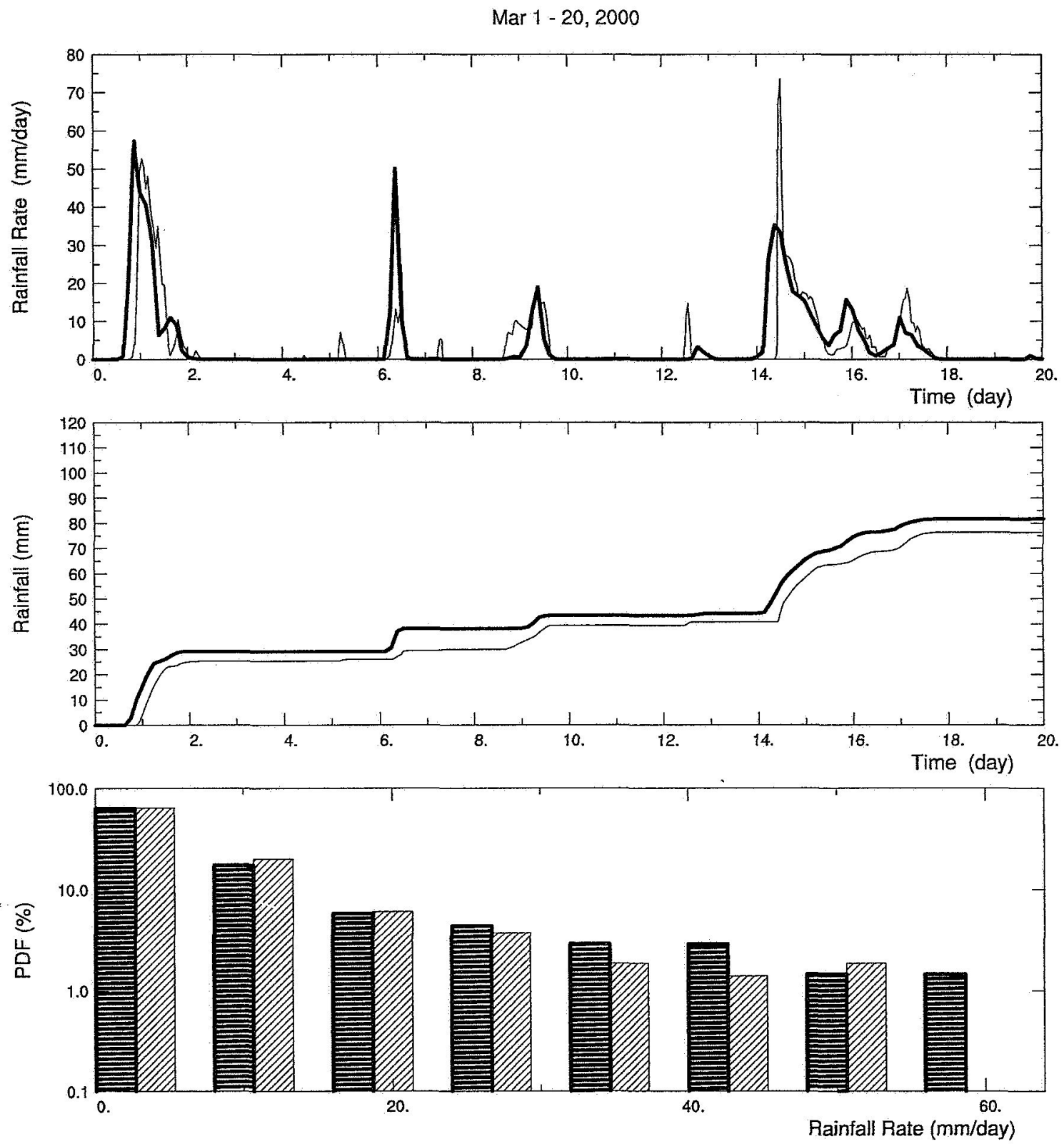

Figure 5 Surface precipitation for the spring 2000 period. Green and black solid lines represent observations and control experiment $\mathrm{C} 00$, respectively. Surface precipitation rate and accumulated rainfall are shown in the upper and middle panes, respectively. The PDF of surface precipitation is shown in the lower pane. 

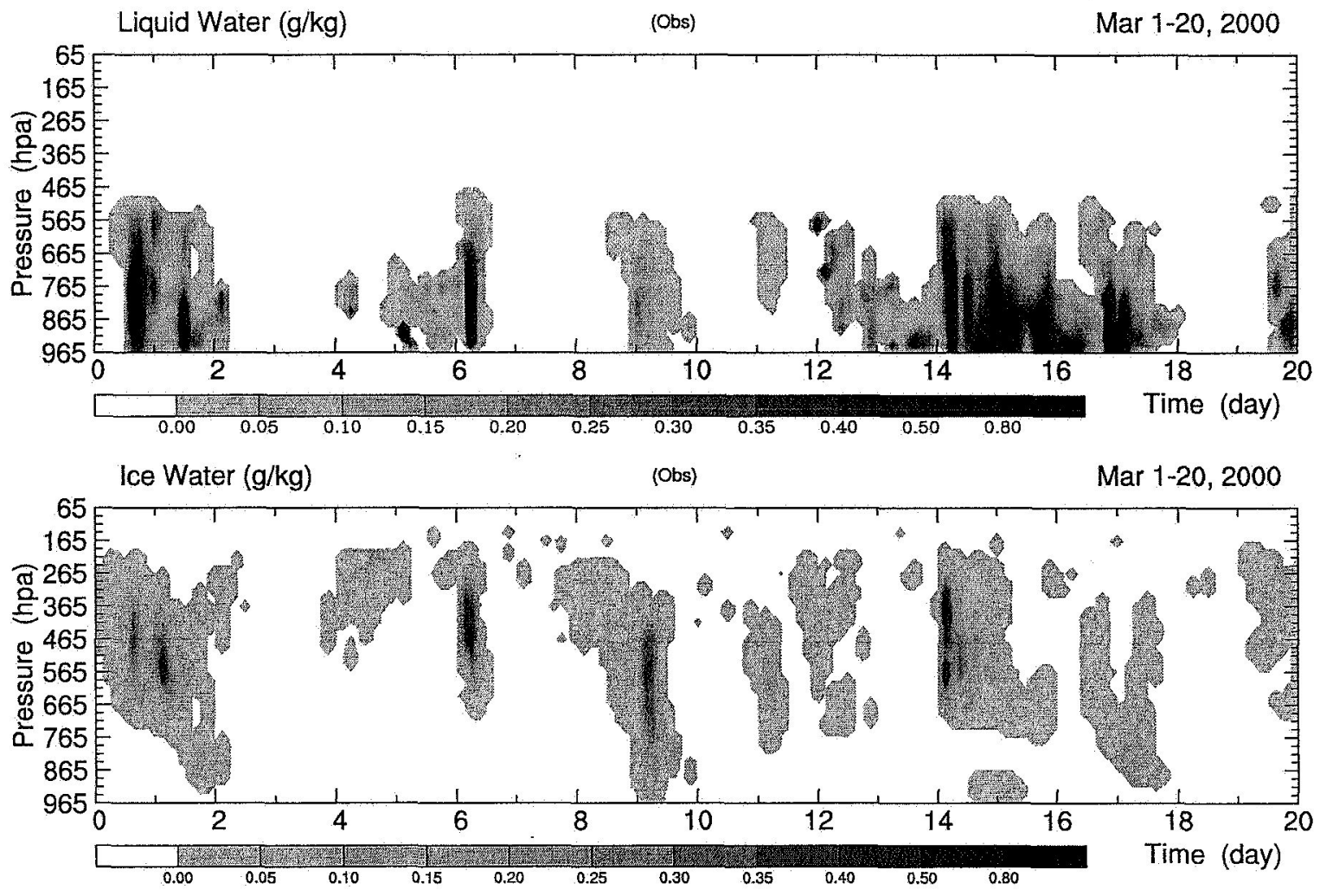

Figure 6 Time-pressure cross sections of retrieved liquid and ice water contents starting from 1730 UTC 1 March 2000. 

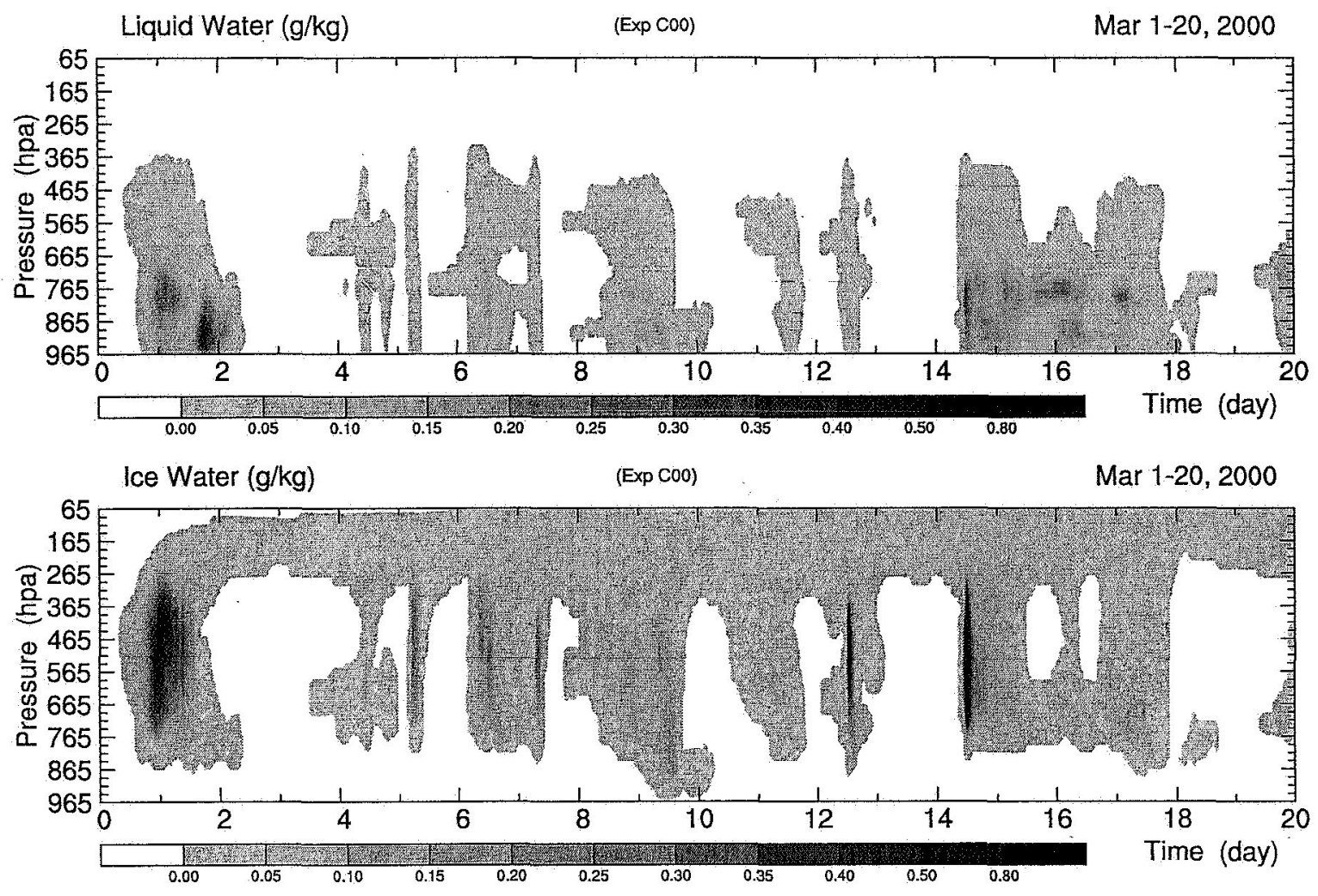

Figure 7 Time-pressure cross sections of liquid and ice water contents obtained from the control experiment $\mathrm{C} 00$ for the spring 2000 period. 

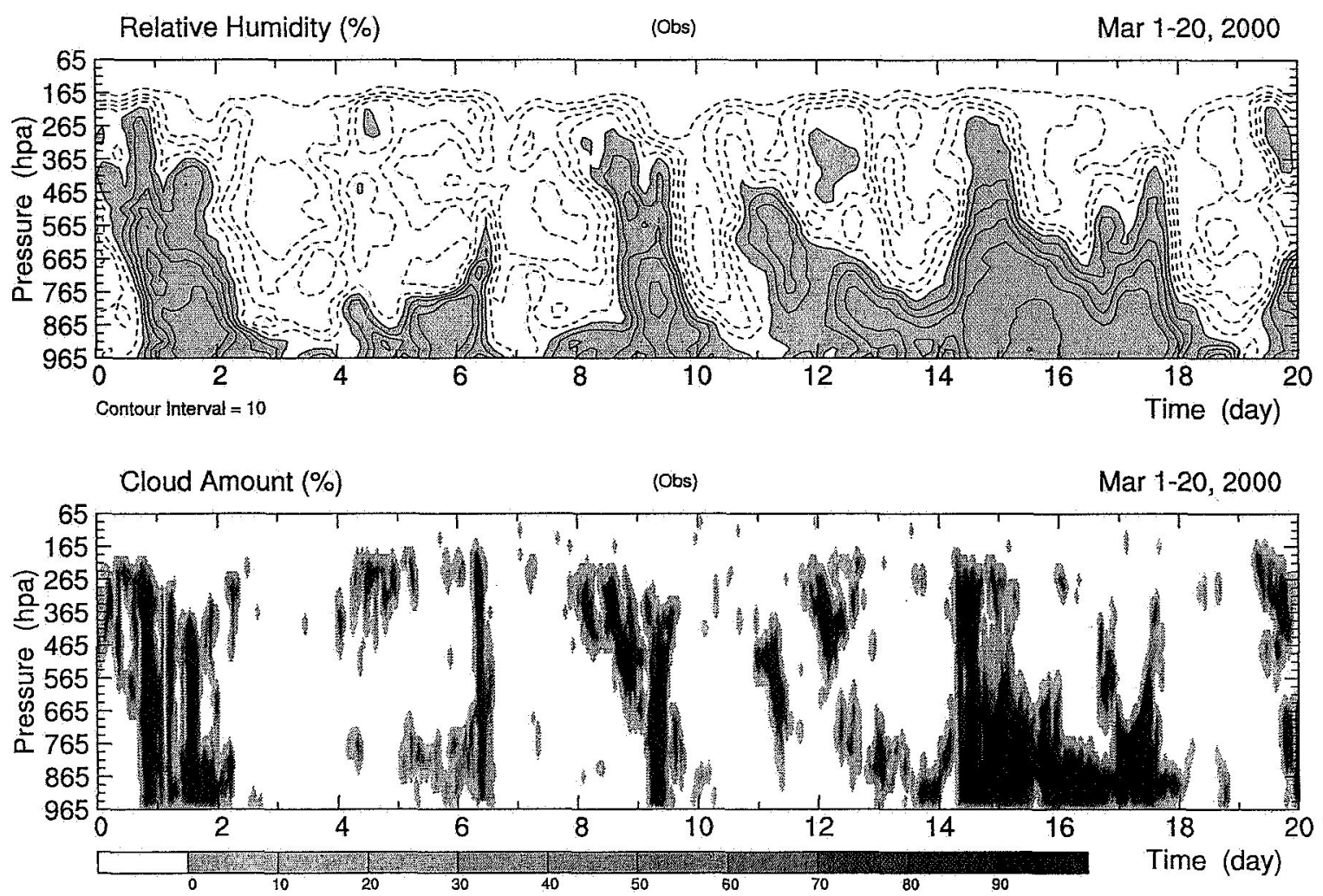

Figure 8 Time-pressure cross sections of observed relative humidity and cloud fraction starting from 1730 UTC 1 March 2000. In the upper part, shaded areas indicate a relative humidity of more than $50 \%$; dashed and solid lines represent the contour levels with relative humidity smaller and larger than $50 \%$, respectively. 

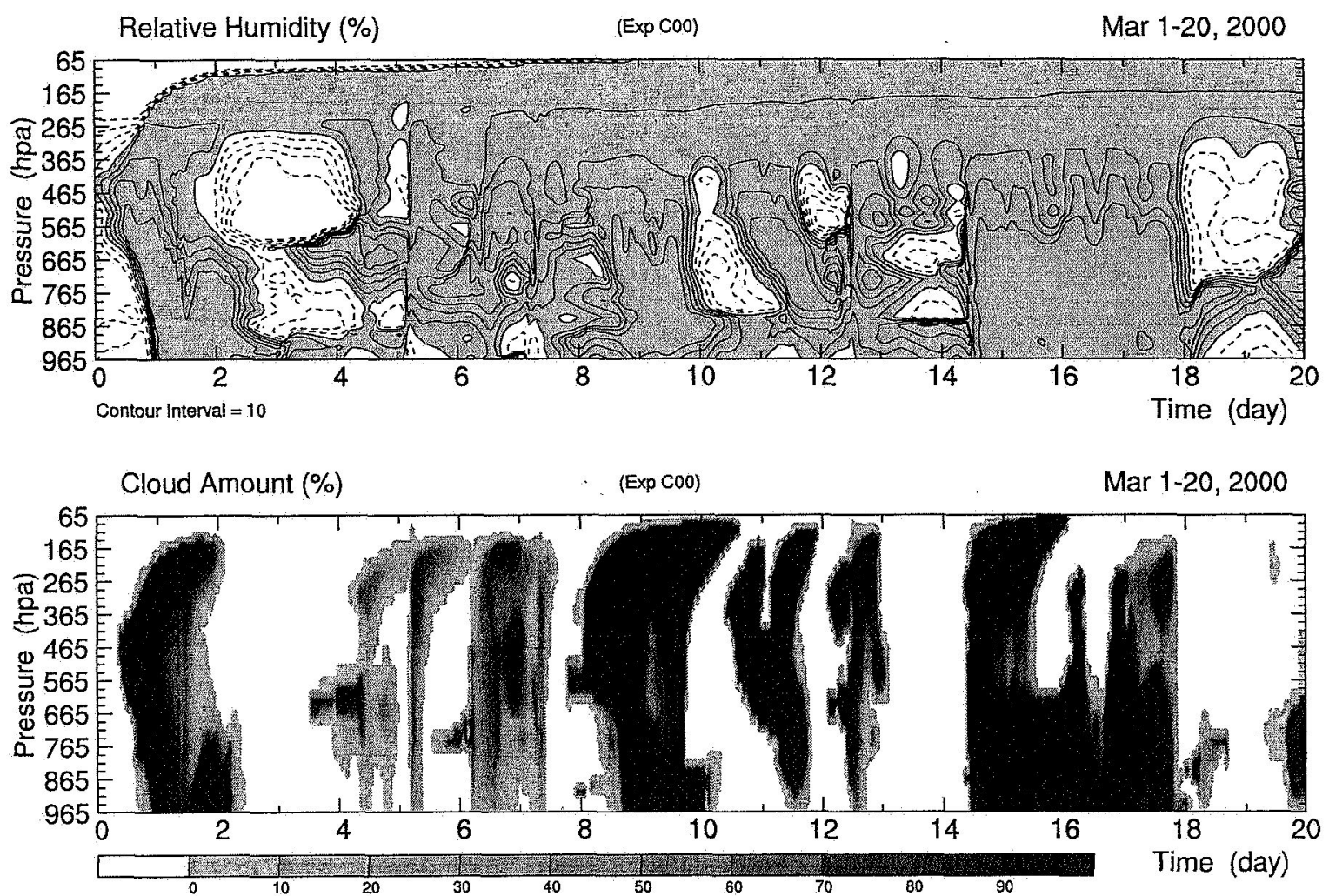

Figure 9 Time-pressure cross sections of relative humidity and cloud fraction from the control experiment $\mathrm{C} 00$ for the spring 2000 period. In the upper part, shaded areas indicate a relative humidity of more than $50 \%$; dashed and solid lines represent the contour levels with relative humidity smaller and larger than $50 \%$, respectively. 
Mar $1-20,2000$

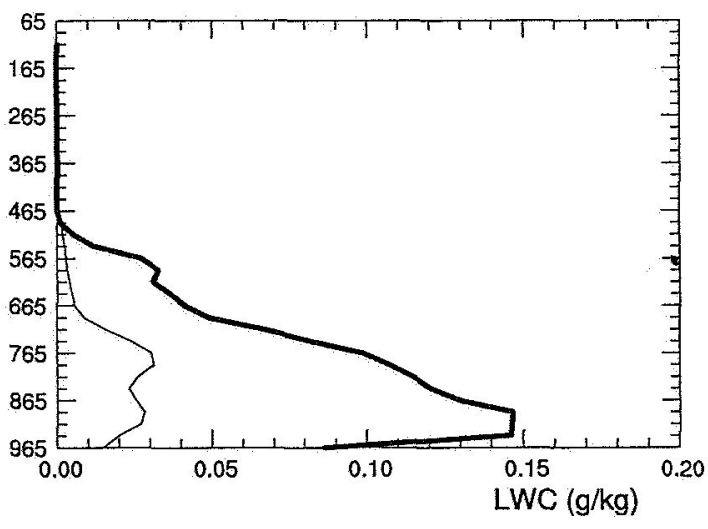

Mar 1-20,2000

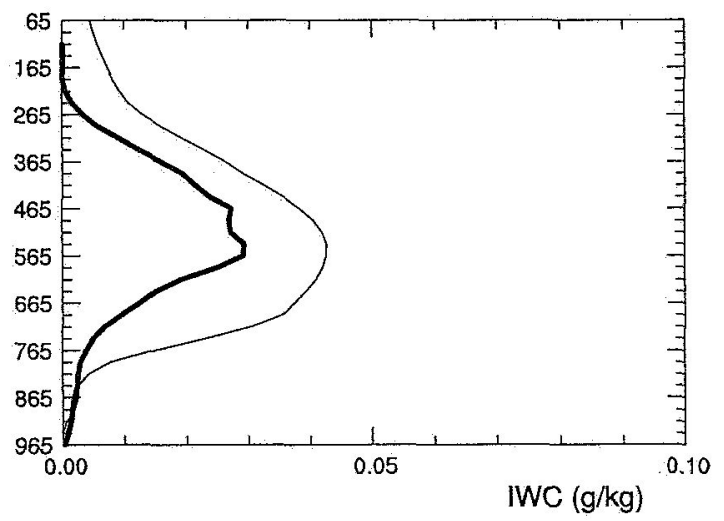

$\operatorname{Mar} 1-20,2000$

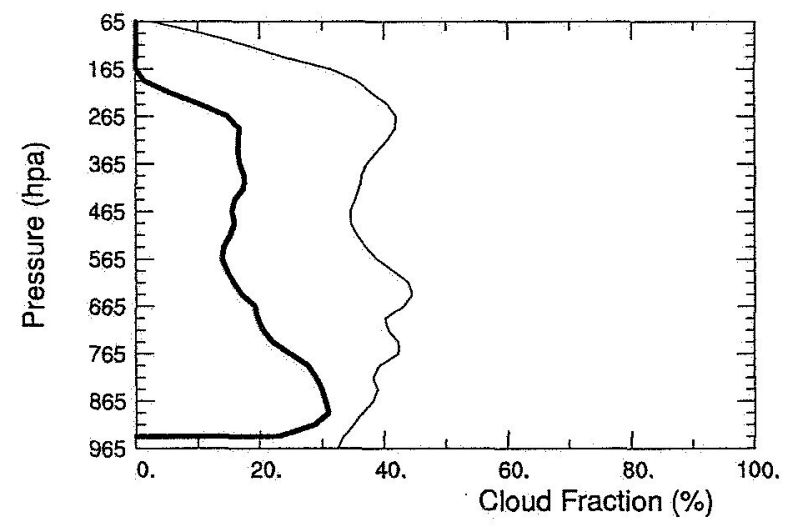

Mar 1-20,2000

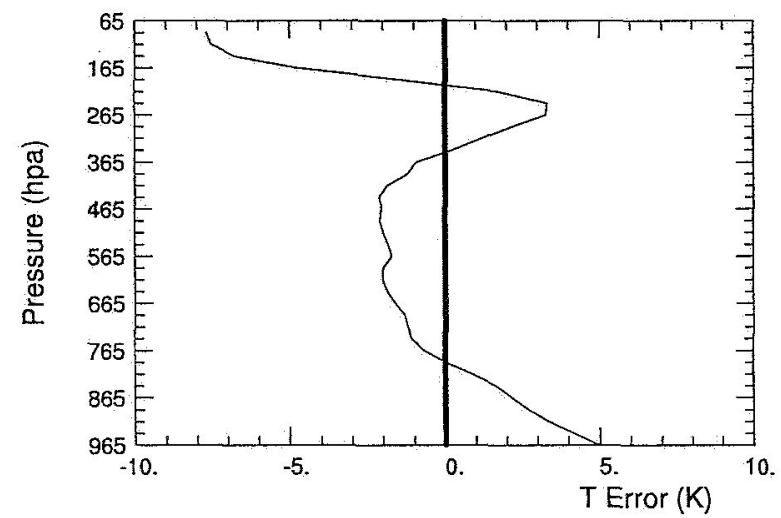

Figure 10 Twenty-day mean profiles of liquid and ice water content, cloud fraction, and air temperature difference between the model and observations against pressure in the 2000 case. Thick and thin lines represent variables from observations and experiment $\mathrm{C} 00$, respectively. 

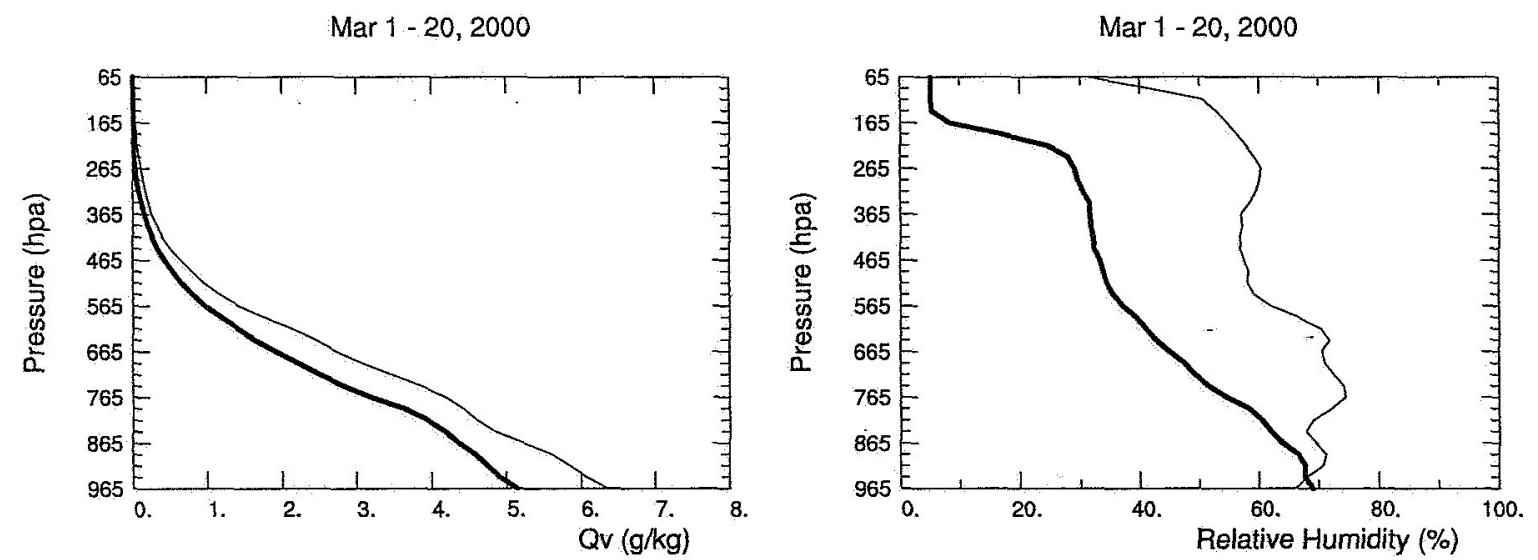

Figure 11 Same as Fig. 10 except for relative humidity and the mixing ratio of water vapor. 

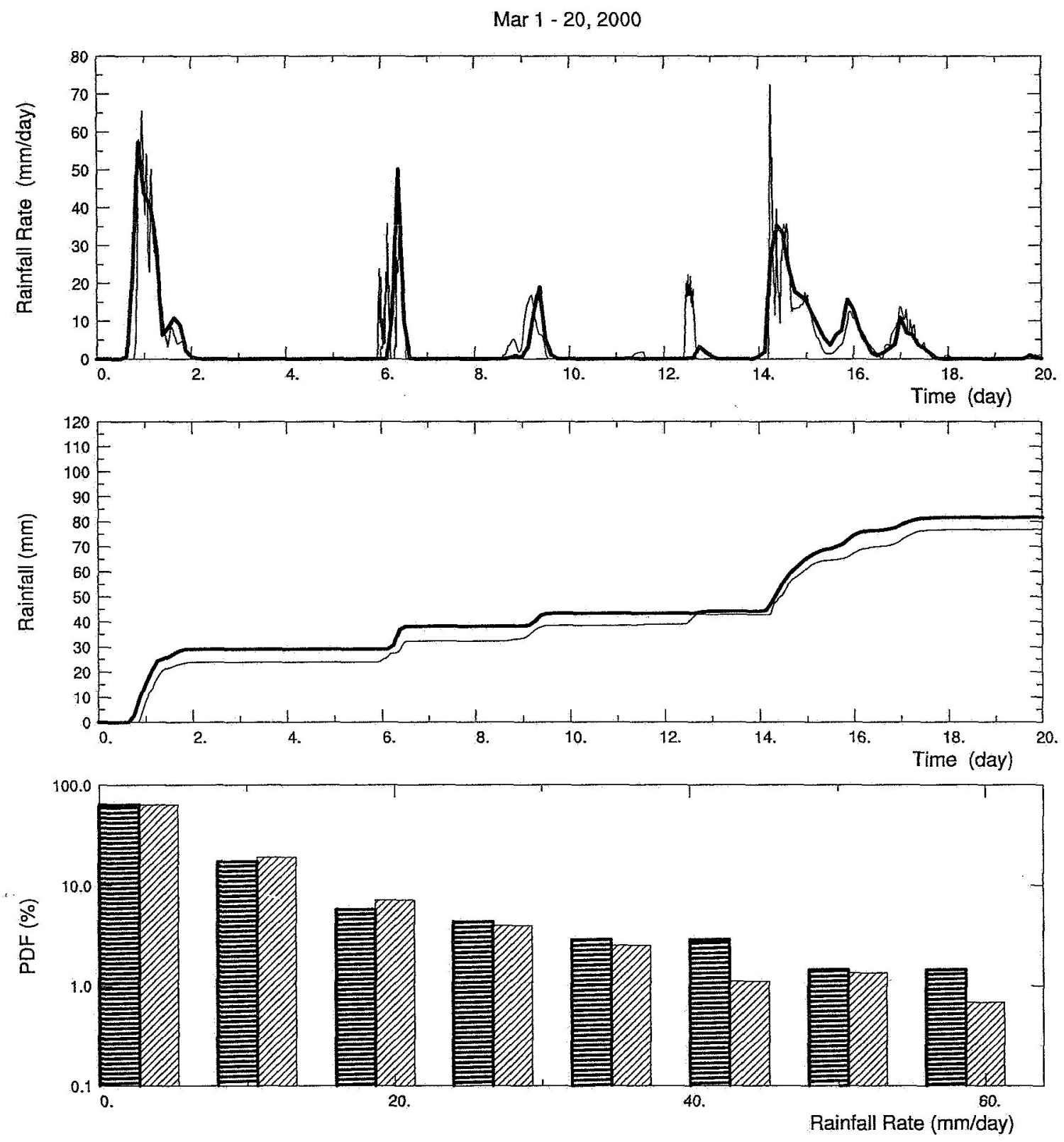

Figure 12 Same as Fig. 5 except for the experiment D00 (a 2D numerical experiment for the 2000 case). 

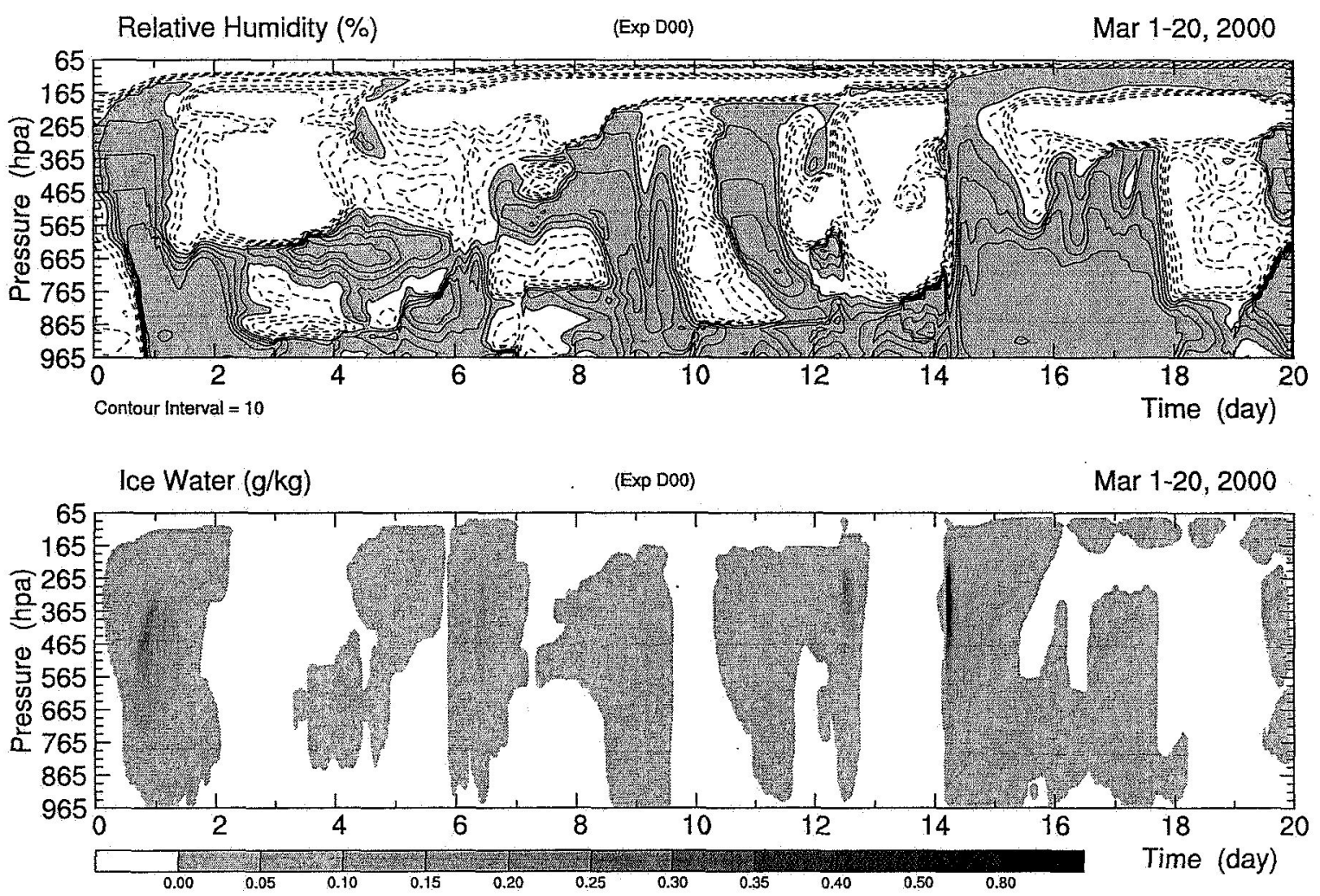

Figure 13 Time-pressure cross-sections of relative humidity and ice water content in experiment D00 (a 2D numerical experiment for the 2000 case). 

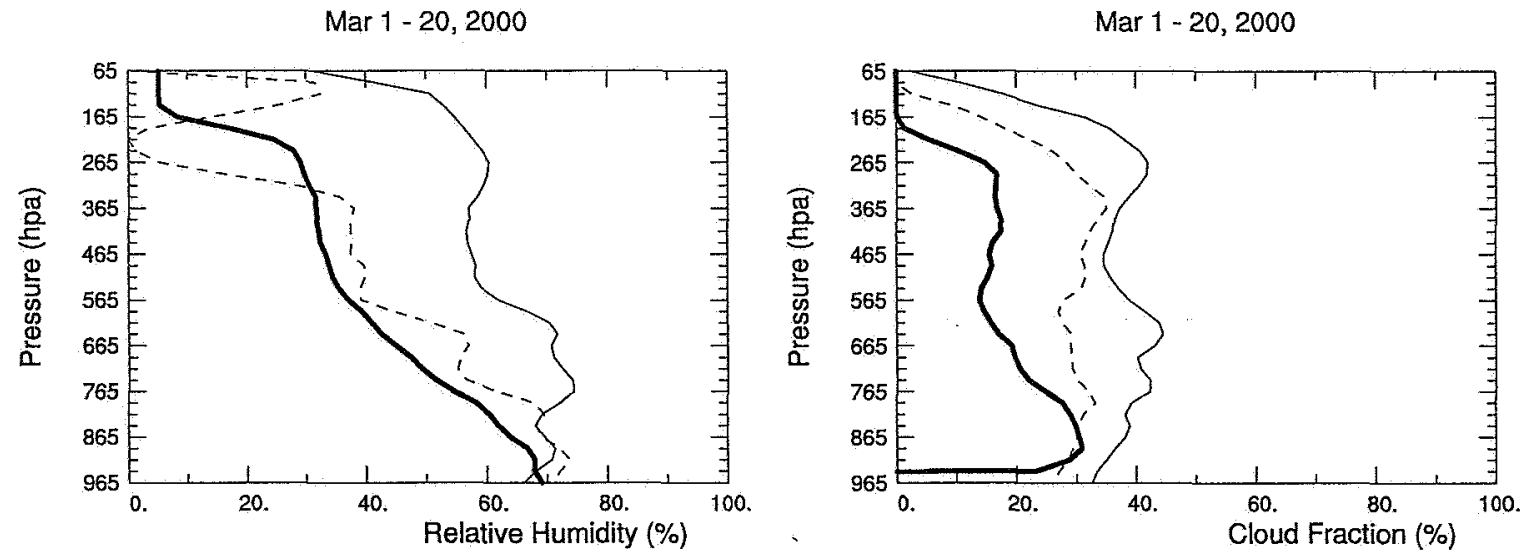

Mar $1-20,2000$

$\operatorname{Mar} 1-20,2000$
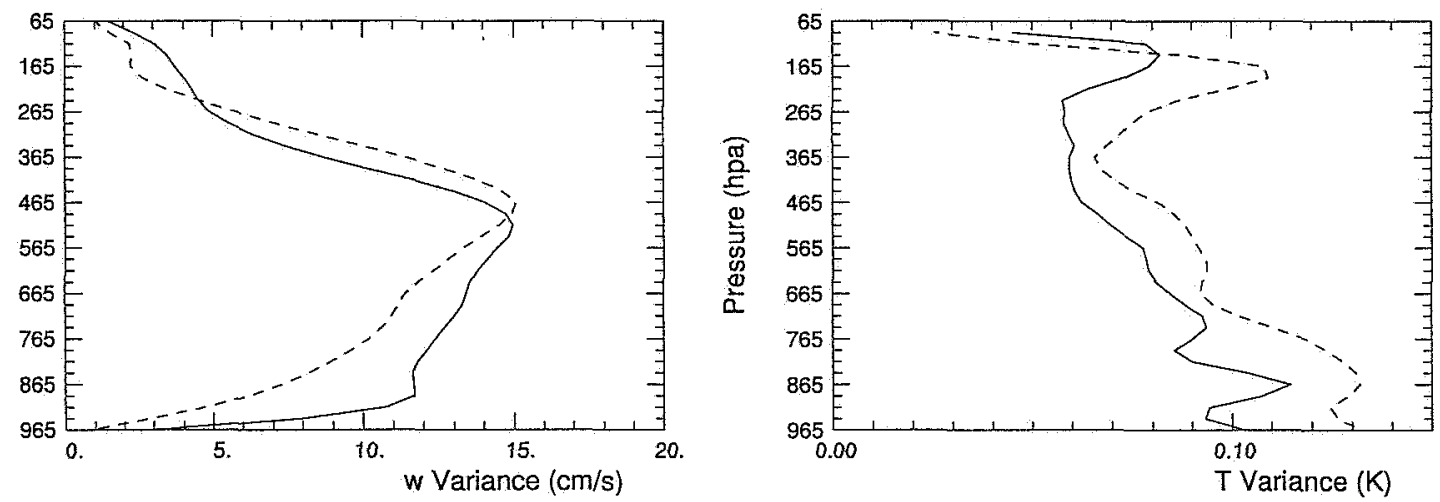

Figure 14 Twenty-day mean profiles of relative humidity, cloud fraction, vertical velocity variance, and temperature variance against pressure in the 2000 case. Thick lines represent observed variables; thin lines variables from experiment $\mathrm{C} 00$; and thin dashed lines variables from experiment D00. 

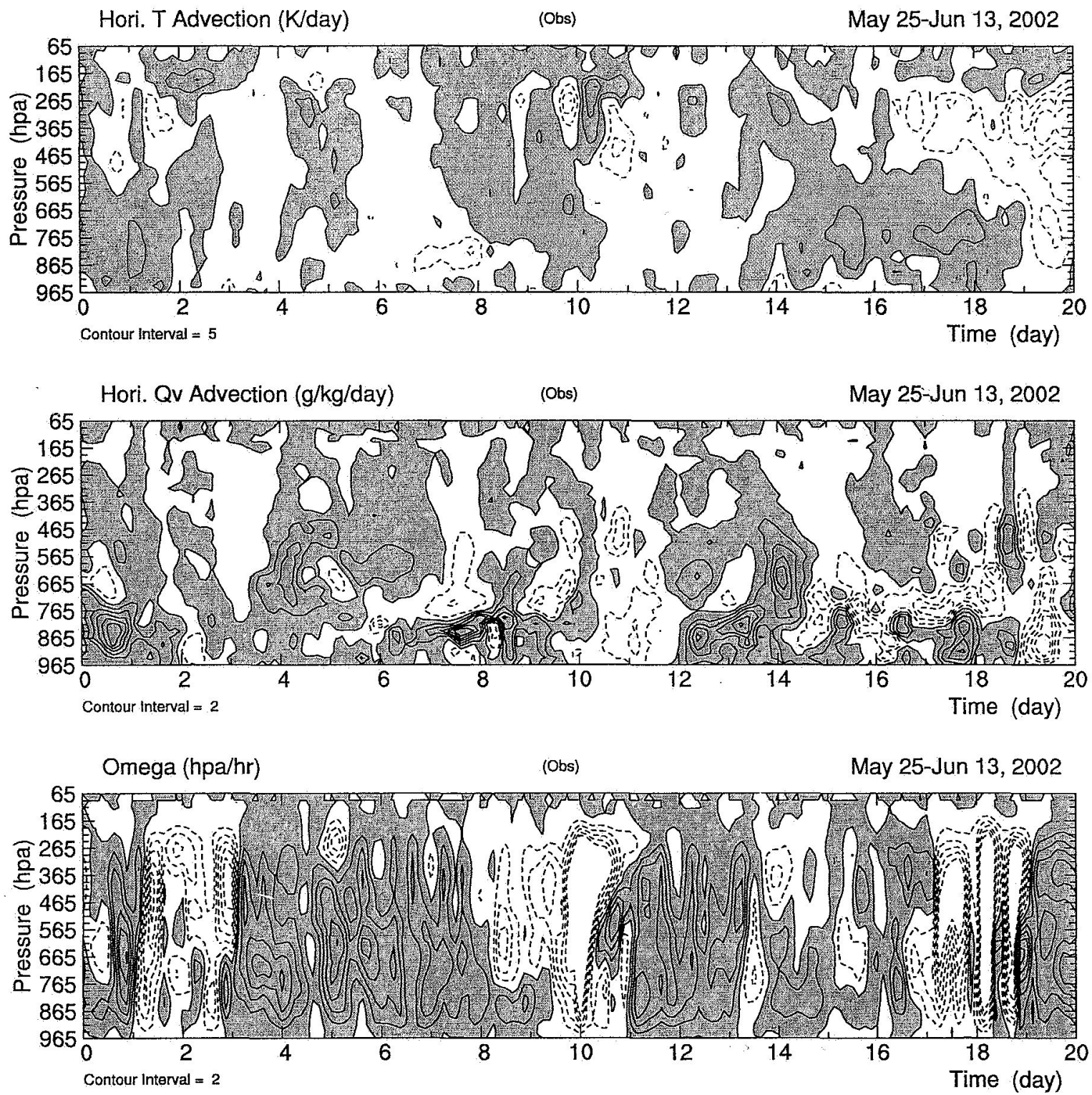

Figure 15 Same as Fig. 4 except for the 2002 case. Data start at 2030 UTC 25 May 2002. 

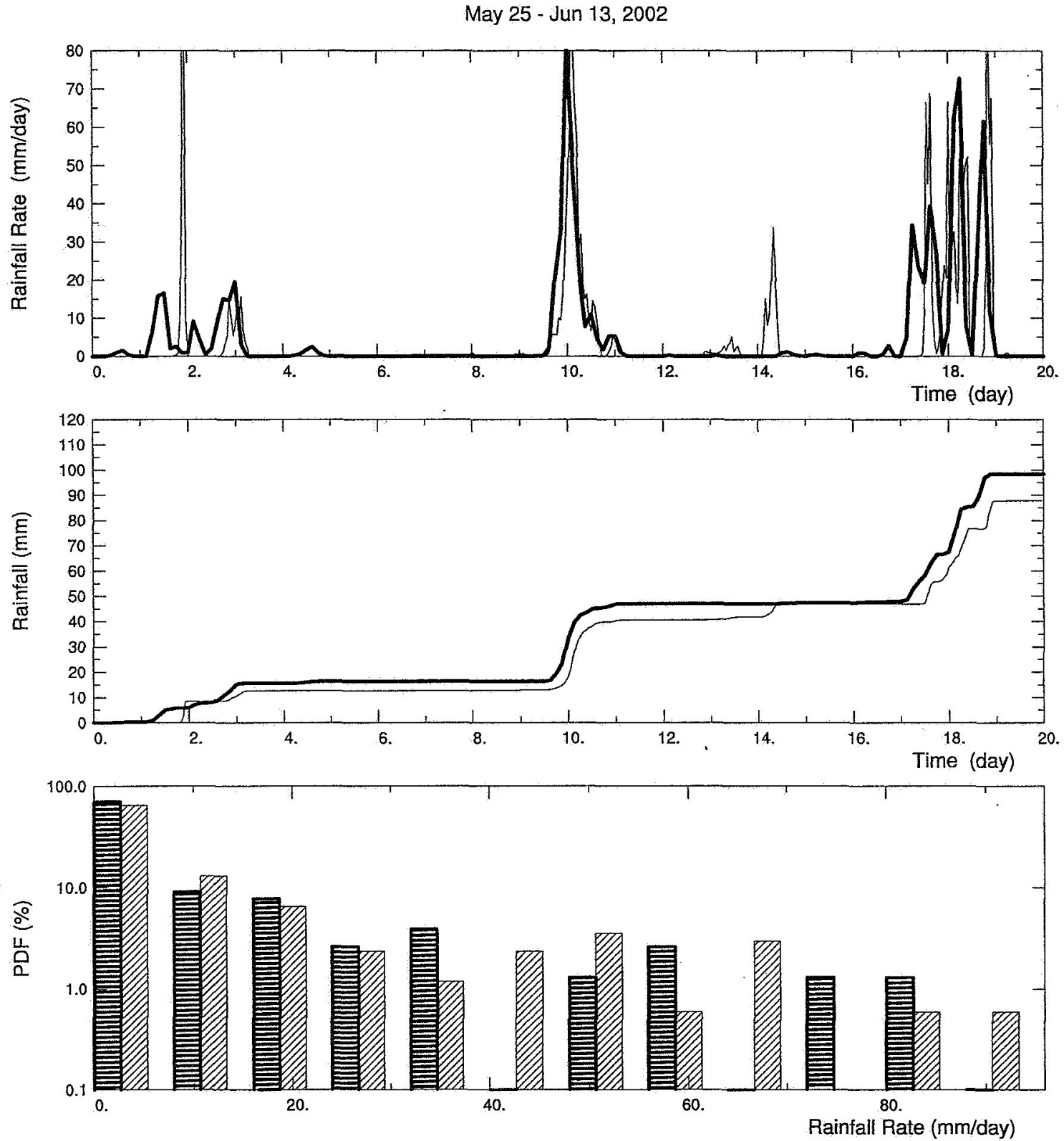

Figure 16 Same as Fig. 5 except for the 2002 case. The numerical experiment is $\mathrm{C} 02$. 

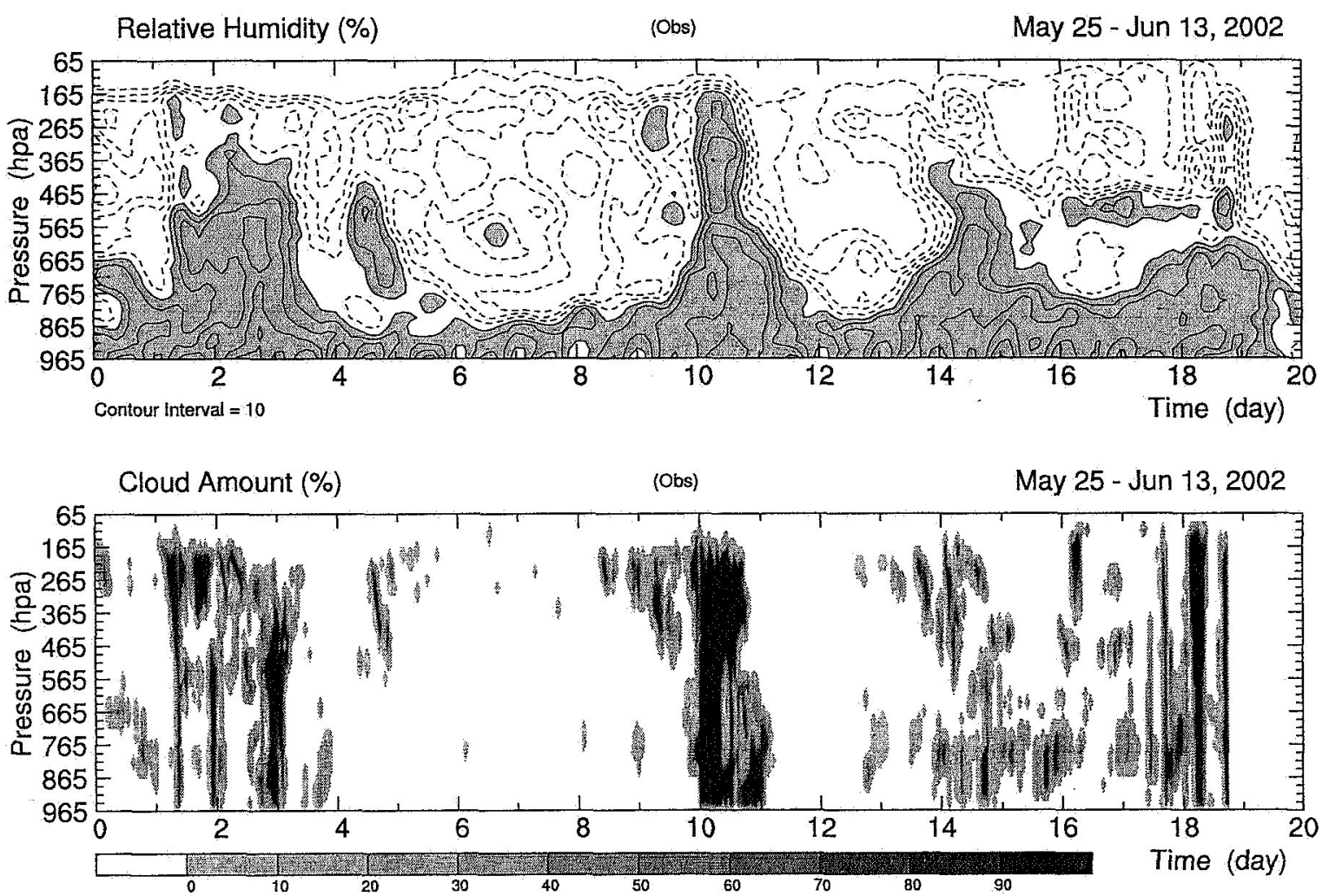

Figure 17 Same as Fig. 8 except for the 2002 case. 

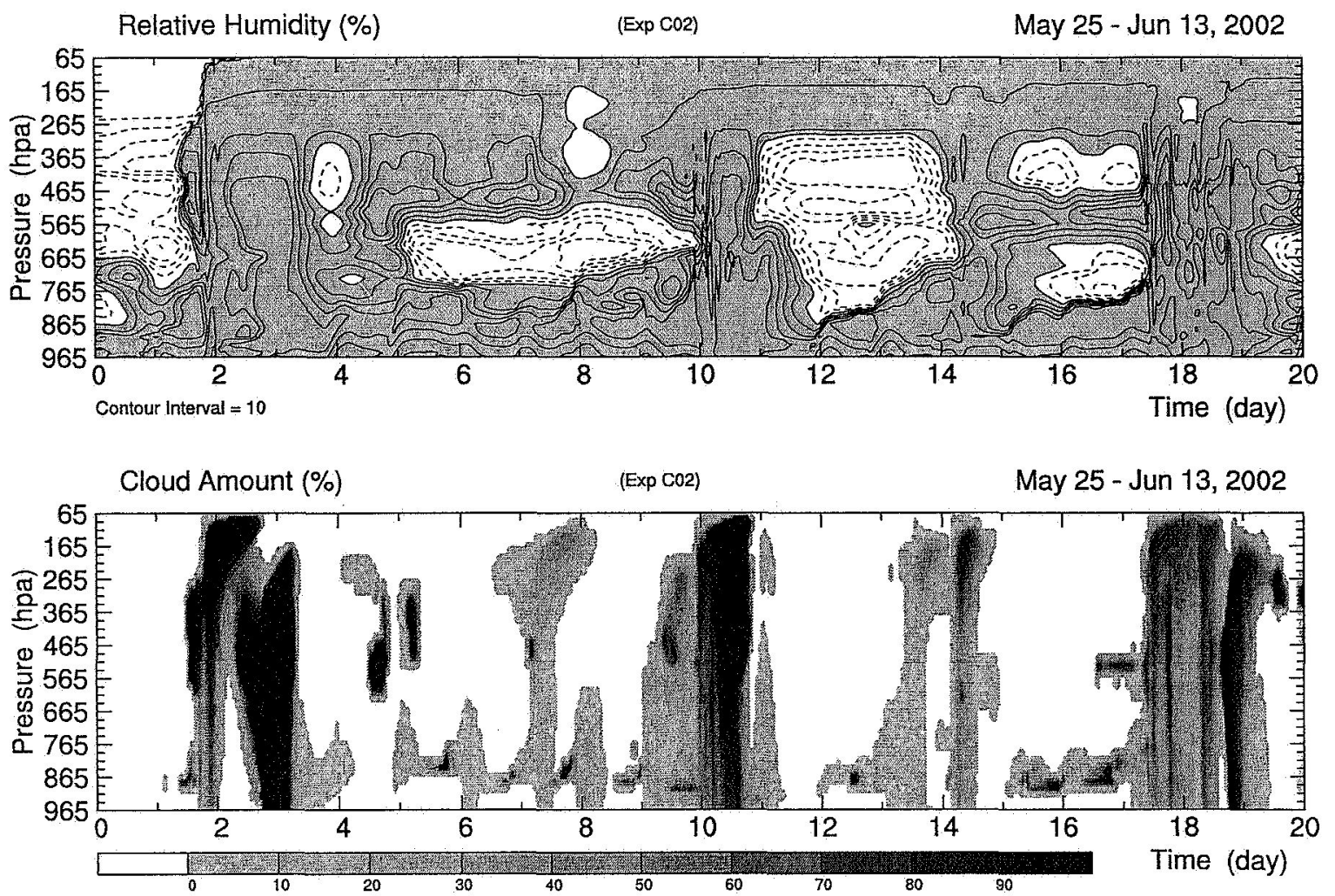

Figure 18 Same as Fig. 9 except for the 2002 case. Data are from the control experiment $\mathrm{C} 02$. 

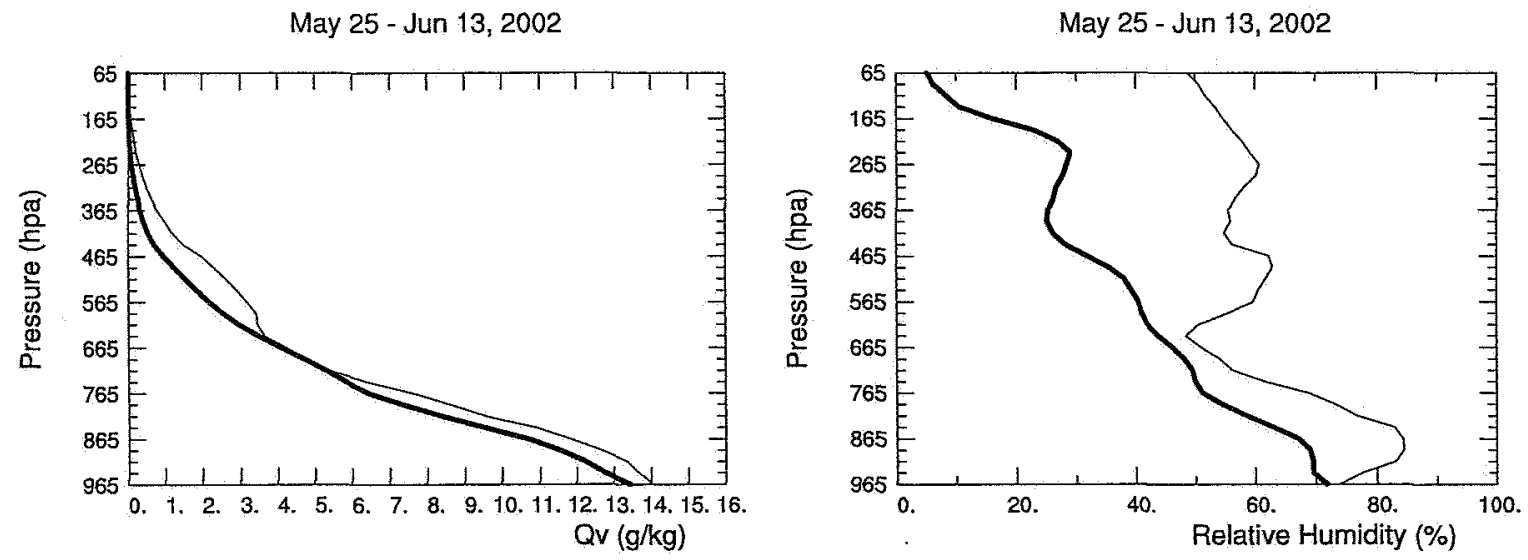

Figure 19 Same as Fig. 11 except for the 2002 case. The numerical experiment is $\mathrm{C} 02$. 

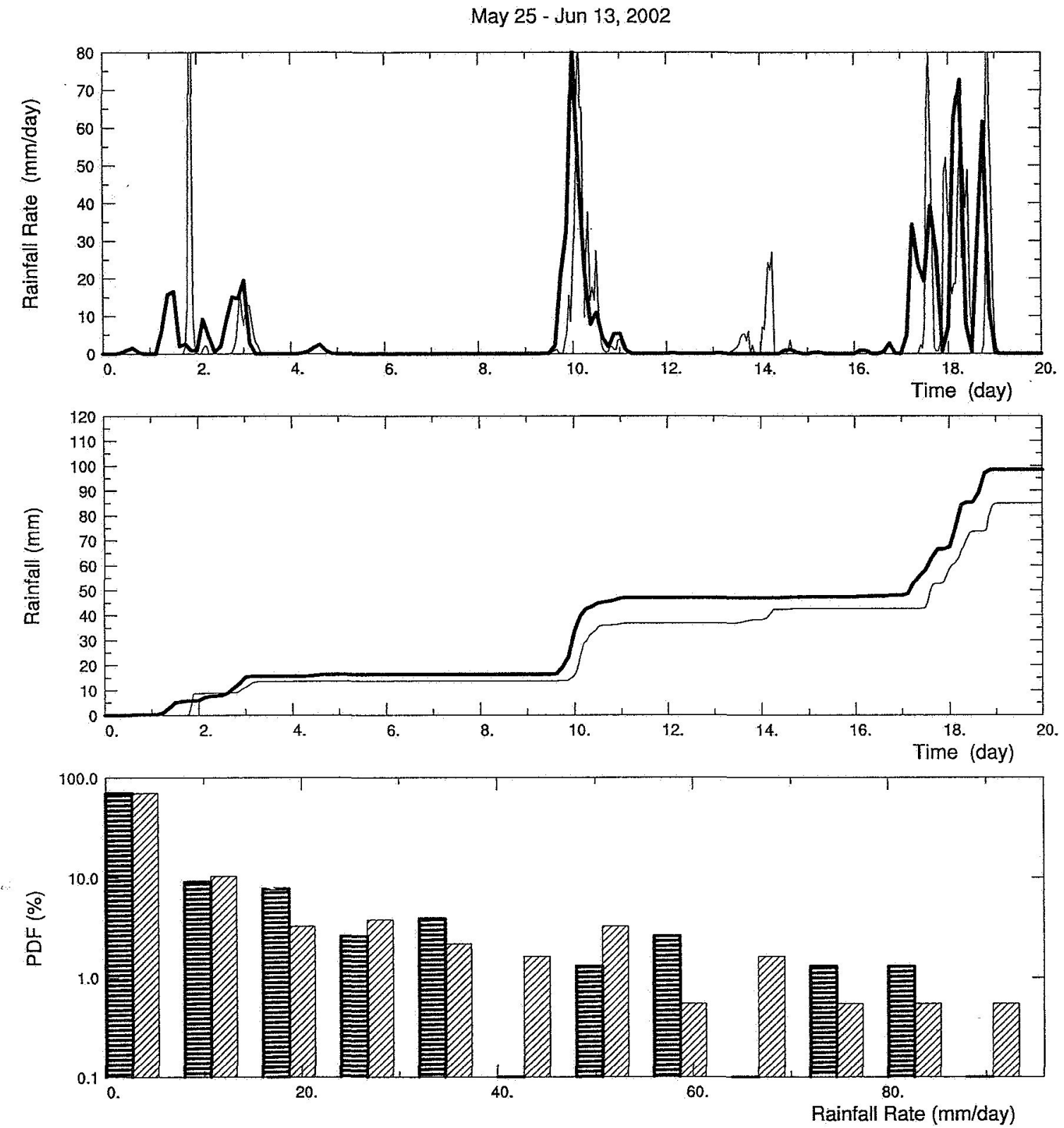

Figure 20 Same as Fig. 16 except for the 2002 case and experiment L02. 

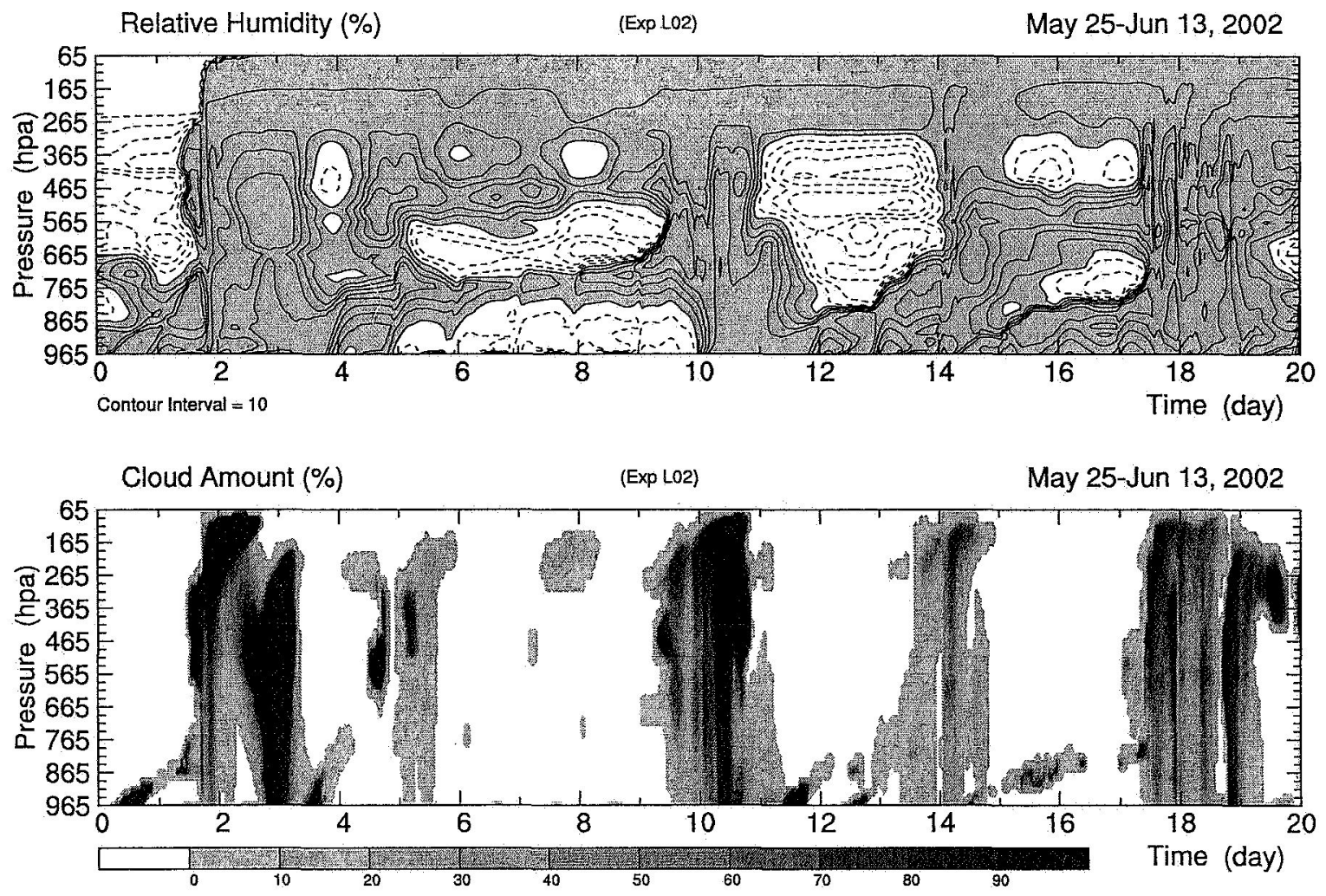

Figure 21 Same as Fig. 18 except for the 2002 case and experiment L02. 